\title{
EFEITOS DOS MACRONUTRIENTES E DO FERRO NO CRESCIMENTO E COMPOSIÇÃO QUÍMICA DA MAMONEIRA (Ricinus communis L.) CULTIVADA EM SOLUÇÕES DE NU'TRIENTES *
}

\author{
AÍdA ItUrRieta RoJAs \\ A. M. Louis NePtune ***
}

\begin{abstract}
RESUMO
Este trabalho foi realizado com a finalidade de estudar os efeitos dos macronutrientes e do micronutriente (ferro) na morfologia, na composição química dos limbos das folhas e das plantas inteiras e no crescimento da mamoneira (Ricinus communis L.), cultivar "Campinas".

As plantas receberam uma solução completa de macro e micronutrientes durante dois meses. Após este período passaram a receber solução de nutrientes com presença e omissão dos macronutrientes e do micronutriente (ferro).

As plantas foram cultivadas em vasos de barro, impermeabilizados internamente, contendo sílica como substrato. Após 2 meses de cultivo nas soluções deficientes, apareceram os sintomas de deficiência de $N, P$, $\mathrm{Ca}, \mathrm{Mg}$, e $\mathrm{Fe}$ e após 3 meses, os sintomas de deficiencia de $\mathrm{K}$ e $\mathrm{S}$, os quais foram descritos.

Em relação ao crescimento das plantas, as seguintes medidas foram tomaaas: aııura, alametro do caule, comprimento do lóbulo central.

As concentrações de $\mathrm{N}, \mathrm{P}, \mathrm{K}, \mathrm{Ca}, \mathrm{Mg}, \mathrm{S}$ e $\mathrm{Fe}$ foram determinados nos limbos das tolhas e nas plantas inteiras. As quantidades em $\mathrm{mg}$ de cada um destes nutrientes absorvidos pelas plantas foram calculadas.
\end{abstract}

\section{INTRODUÇÃO}

A mamoneira (Ricinus communis L.), conhecida desde os tempos antigos, era lavoura de fundo de quintal e o óleo extraído de suas sementes era utilizado para iluminar as casas. Com o advento da I Guerra Mundial e principalmente da II Guerra Mundial, a mamo-

* Entregue para publicação em 20/1/1971. Parte do trabalho apresentado pelo primeiro autor com Tese à Escola Superior de Agricultura "Luiz de Queiroz" para a obtenção do título de Magister Scientiae.

* Ministério de Agricultura, Departamento de Defesa Agrícola, Santiago, Chile.

*** Departamento de Solos e Geologia, ESALQ-USP. Piracicaba, S.P.

$* * * *$ Agradecimentos são devidos aos Dr. Roland Vencovsky, Docente Livre do Departamento de Genética e do Eng.o Agr.o Vivaldo F. da Cruz, Professor Assistente do Departamento de Matemática e Estatística, pela colaboração na análise estatística dos dados; aos Srs. Angelo Smaniotto, Vinicius Ferraz e Armando Porta, pelos serviços prestados e a Srta. Maria Edine de Gáspari, pelo serviço de datilografia. 
neira passou a ocupar uma posição de destaque, devido aos múltiplos usos que lhe foram encontrados. Então surgiram maiores interesses no melhoramento genético para a obtenção de novas variedades de porte médio e indeiscentes e na mecanização da cultura (KRUG \& MENDES, 1942 ; CANECHIO, 1958 ; SCHOEN-LEBER, 1960 ; NAKAMAE, 1968 e MIALHE, 1969).

O óleo da mamoneira serve, entre outros, como lubrificante para aviões a jato, fluidos hidráulicos, no preparo de tintas e vernizes, na fabricação de plásticos, de produtos farmaceuticos, de sabões. Ainda mais, a torta, resíduo da extração do óleo, é utilizada como adubo (ZIMMERMAN, 1958).

Com a expansão do consumo industrial do óleo de semente da mamoneira as lavouras passaram a dar lugar a cultivos em bases economicas.

A produção mundial de sementes desta oleaginosa em 1.000 toneladas métricas durante o período de 1960 - 1964 a 1968, de acôrdo com os dados publicados na World Agricultural Production and Trade, Rio de Janeiro de 1969, foi a seguinte:

Anos

Produção em 1.000 ton. métricas

\begin{tabular}{cc}
\hline $1960-1964$ & 678 \\
1965 & 788 \\
1966 & 781 \\
1967 & 709 \\
1968 & 875 \\
\hline
\end{tabular}

O Brasil é atualmente um dos principais produtores de sementes de mamoneira e contribui com 40 a $50 \%$ da exportação mundial. O país exportou de janeiro a junho de 1968, 95.000 toneladas métricas de sementes de mamona.

Os Estados que se destacam com maiores produtores de mamona são: São Paulo, Bahia e Paraná.

A cultura desta importante oleaginosa apresenta problemas economicos e técnicos; por outro lado não existe quase nada a respeito da nutrição mineral desta oleaginosa. O único trabalho que se conhece sobre o assunto é o de TUCKER, 1952. Em vista disso, realizamos o presente trabalho, em casa de vegetação, tendo em mente, os seguintes objetivos:

1. Observar e descrever os sintomas morfológicos que aparecem com a presença e carencia de nitrogenio, fósforo, potássio, cálcio, magnésio, enxofre e ferro. 
2. Verificar os efeitos da omissão e presença daqueles macronutrientes e do ferro no crescimento das plantas.

3. Determinar, através da análise química, a concentração do nitrogenio, fósforo, potássio, cálcio, magnésio e enxofre, nos limbos das folhas e nas plantas inteiras com e sem carencia dos macronutrientes e do ferro.

\section{MATERIAL E MÉTODOS}

\section{Delineamento Experimental}

O delineamento inicial foi inteiramente casualizado e constou de 14 tratamentos repetidos tres vezes. Sete tratamentos receberam uma solução completa de macro e micronutrientes e nos outros sete, eram omitidos um por vez, os seguintes nutrientes: nitrogenio, fósforo, potássio, cálcio, magnésio, enxofre e ferro. Os tratamentos eram os seguintes:

1) $\mathrm{C}_{1}$, solução de macro e micronutriente

2) $-\mathrm{N}$, solução de macro e micronutriente, com omissão de nitrogenio

3) $\mathrm{C}_{2}$, solução de macro e micronutriente

4) -P , solução de macro e micronutriente, com omissão de fósforo

5) $\mathrm{C}_{3}$, solução de macro e micronutriente

6) $-\mathrm{K}$, solução de macro e micronutriente, com omissão de potássio

7) $\mathrm{C}_{4}$, solução de macro e micronutriente

8) $-\mathrm{S}$, solução de macro e micronutriente, com omissão de enxofre

9) $C_{\tilde{5}}$, solução de macro e micronutriente

10) - $\mathrm{Ca}$, solução de macro e micronutriente, com omissão de cálcio

11) $C_{6}$, solução de macro e micronutriente

12) $-\mathrm{Mg}$, solução de macro e micronutriente, com omissão de magnésio

13) $\mathrm{C}_{7}$, solução de macro e micronutriente

14) - Fe, solução de macro e micronutriente, com omissão de ferro.

O fato de ter um tratamento completo para cada tratamento deficiente em um dos nutrientes já mencionados, estriba no seguinte: pensou-se que as plantas deficientes podiam manifestar os sintomas 
em épocas bem diferentes uma das outras e isso nos permitiria seguir melhor o crescimento das plantas, as concentrações nos diferentes nutrientes através do seu ciclo vegetativo. Porém, isso não se verificou.

Aos 28 de outubro de 1969, os tratamentos $-\mathrm{N},-\mathrm{P}, \quad-\mathrm{Ca},-\mathrm{Mg}$ mostraram sintomas evidentes de deficiencia e foram retiradas juntamente os tratamentos completos respectivos, $\mathrm{C}_{1}, \mathrm{C}_{2}, \mathrm{C}_{5}$ e $\mathrm{C}_{6}$. No dia 13 de novembro de 1969, os tratamentos $-\mathrm{Fe}, \mathrm{C}_{7}$ foram retirados e no dia 21 de novembro, os restantes $-\mathrm{K},-\mathrm{S}, \mathrm{C}_{3}$ e $\mathrm{C}_{4}$. Diante destes fatos, um novo esquema foi feito e somente que, desta vez, os tratamentos completos eram repetidos quatro vezes. Os números de tratamentos passaram a ser dez, divididos em tres grupos, 5, 2 e 3 tratamentos, respectivamente.

O agrupamento veio a ser o seguinte:

1. ${ }^{\circ}$ Grupo de Tratamentos:

$\mathrm{C}_{1}$ (4 vasos eram escolhidos ao acaso entre os tratamentos $C_{1}$, $\mathrm{C}_{2}, \mathrm{C}_{\overline{5}}$ e $\mathrm{C}_{6}$ ).

$-\mathrm{N}$

$-\mathrm{P}$

$-\mathrm{Ca}$

$-\mathrm{Mg}$

2. ${ }^{\circ}$ Grupo de Tratamentos:

$-\mathrm{Fe}$

$\mathrm{C}_{2}$ (4 vasos eram escolhidos ao acaso entre os tratamentos $\mathrm{C}_{1}$, $\mathrm{C}_{2}, \mathrm{C}_{\bar{i}}, \mathrm{C}_{6}$ e $\mathrm{C}_{\overline{\mathrm{i}}}$ ).

3. ${ }^{\circ}$ Grupo de Tratamentos:

$-\mathrm{K}$

$-\mathrm{S}$

$C_{3}$ (4 vasos eram escolhidos ao acaso entre os tratamentos $C_{3}$ e $\mathrm{C}_{4}$ ).

\section{Características do Cultivar "Campinas" utilizado no Experimento}

As sementes de mamoneira do cultivar "Campinas" eram provenientes da Seção de Oleaginosas do Instituto Agronomico de Campinas. Este cultivar, caracteriza-se por apresentar porte médio, ciclo vegetativo de 160 a 180 dias, elevada capacidade produtiva, frutos indeiscentes, 50 a $52 \%$ de óleo na semente e queda das folhas na ocasião da colheita (VASCONCELLOS ROCHA, 1964). 


\section{Obtenção das Mudas}

Para a germinação da semente, utilizou-se uma caixa de cimento de $80 \mathrm{~cm}$ de comprimento, $70 \mathrm{~cm}$ de largura e $11 \mathrm{~cm}$ de altura. Sobre uma camada de areia lavada com $\mathrm{HC1}$, de $8 \mathrm{~cm}$ de altura, foram colocadas no dia 24 de abril de 1969, as sementes da mamona, as quais foram cobertas com outra camada de areia de $2 \mathrm{~cm}$. Realizou-se a rega duas vezes ao dia com água desmineralizada.

A germinação principiou em 15 de maio de 1969. Procedeu-se ao transplante em 25 de maio de 1969, quando as mudas apresentavam duas folhas cotiledonares.

\section{Vasos Utilizados para receber as mudas}

Os vasos utilizados eram de barro, de forma cilíndrica, tendo as seguintes dimensões: $26 \mathrm{~cm}$ de diametro na parte superior, $16,5 \mathrm{~cm}$ de diametro na parte inferior e $26 \mathrm{~cm}$ de altura. Eram pintados internamente com uma tinta impermeabilizante chamada Neutrol, e era utilizado como substrato para suporte das plantas $3,450 \mathrm{~kg}$. de quartzo moido.

No fundo dos vasos, colocou-se uma camada de pedra de um $\mathrm{cm}$ de diametro até uma altura de $5 \mathrm{~cm}$, com a finalidade de permitir maior aeração às raízes das plantas e melhor escoamento das soluções de nutrientes.

$\mathrm{Na}$ parte inferior dos vasos, encontrava-se um orifício pelo qual escoavam as soluções de nutrientes, as quais eram recolhidas por meio de uma tubu'ação de plástico, em garrafas de dois litros de capacidade, de cor ambar. Antes de proceder as regas, as soluções de nutrientes contidas nas garrafas coletoras eram sempre completadas a um litro. As regas efetuavam-se duas vezes por dia, porém em dias quentes $\left(31^{\circ}\right.$ a $\left.35^{\circ} \mathrm{C}\right)$, efetuavam-se até quatro vezes ao dia.

\section{Soluções de Nutrientes}

Quando no transplante das mudas, em 25 de maio de 1969, estas receberam a metade da solução n. ${ }^{\circ} 1$ de HOAGLAND \& ARNON, 1950, porém o ferro foi adicionado na forma de $\mathrm{Fe}$ - $\mathrm{Na}$ - EDTA a 5\%.

No dia 10 de agosto de 1969, as plantas apresentavam desenvolvimento desejado e passou-se ao sorteio dos vasos que deviam receber os diferentes tratamentos e consequentemente as soluções de nutrientes correspondentes, como se pode ver na Tabela 1. 
TABELA 1 - Mililitros das soluções de reserva utilizados na composição de um litro da solução nutritiva dos diferentes tratamentos

\begin{tabular}{|c|c|c|c|c|c|c|c|c|}
\hline $\begin{array}{l}\text { soluçōes } \\
\text { normais }\end{array}$ & $\begin{array}{l}\text { trata- } \\
\text { mento } \\
-\mathrm{N}\end{array}$ & $\begin{array}{l}\text { trata- } \\
\text { mento } \\
-P\end{array}$ & $\begin{array}{l}\text { trata- } \\
\text { mento } \\
--K\end{array}$ & $\begin{array}{l}\text { trata- } \\
\text { mento } \\
\text { - }\end{array}$ & $\begin{array}{l}\text { trata- } \\
\text { mento } \\
\text { - Ca }\end{array}$ & $\begin{array}{l}\text { trata- } \\
\text { mento } \\
-\mathrm{Mg}\end{array}$ & $\begin{array}{l}\text { trata- } \\
\text { mento } \\
-\mathrm{Fe}\end{array}$ & $\begin{array}{l}\text { com- } \\
\text { pleta }\end{array}$ \\
\hline $\mathrm{KNO}_{3}$ & & 6 & & 2 & 5 & 3 & 4 & 4 \\
\hline $\mathrm{Ca}\left(\mathrm{NO}_{3}\right)_{2}$ & & 4 & 6 & 4 & & 5 & 4 & 4 \\
\hline $\mathrm{Mg}\left(\mathrm{NO}_{3}\right)_{2}$ & & & & 3 & 1 & & 2 & 2 \\
\hline $\mathrm{K}_{2} \mathrm{SO}_{4}$ & 2 & & & & & 2 & 2 & 2 \\
\hline $\mathrm{Mg}\left(\mathrm{H}_{2} \mathrm{PO}_{4}\right)_{2}$ & 1 & & 1 & & 1 & & 2 & 2 \\
\hline $\mathrm{CaSO}_{4}$ & 1 & & & & & 1 & 1 & 1 \\
\hline $\mathrm{Na}_{2} \mathrm{SO}_{4}$ & & & & & & & 1 & 1 \\
\hline $\mathrm{KH}_{2} \mathrm{PO}_{4}$ & 1 & & & 2 & 1 & 1 & & \\
\hline $\mathrm{KOH}$ & 1 & & & 1 & & & & \\
\hline $\mathrm{Ca}(\mathrm{OH})_{2}$ & 1 & & & & & & & \\
\hline $\mathrm{MgSO}_{4}$ & 1 & 3 & 3 & & 3 & & & \\
\hline $\mathrm{CaCl}_{2}$ & 1 & & & & & & & \\
\hline $\mathrm{MgC1}_{2}$ & 1 & & & & & & & \\
\hline $\mathrm{NaNo}_{3}$ & & 1 & 1 & 1 & 1 & & & \\
\hline $\mathrm{NaH}_{2} \mathrm{PO}_{4}$ & & & 1 & & & 1 & & \\
\hline $\mathrm{KC} 1$ & & & & 1 & & & & \\
\hline Micronutrientes & 1 & 1 & 1 & 1 & 1 & 1 & 1 & 1 \\
\hline Fe-Na-EDTA 5\% & $1-2$ & $1-2$ & $1-2$ & $1-2$ & $1-2$ & $1-2$ & & $1-2$ \\
\hline $\mathrm{NaOH} 0,1 \mathrm{~N}$ & & & 2,5 & & 3 & 2,5 & & 3 \\
\hline
\end{tabular}

Antes de colocar as soluções de nutrientes correspondentes aos diferentes tratamentos, procedeu-se à eliminação de qualque acumulação de sais, fazendo passar em cada vaso cinco litros de água desmineralizada.

Todas as soluções de macro e micronutrientes para os diferentes tratamentos foram preparados a partir das soluções normais dos sais P. A. Os mililitros tomados destas soluções para preparar um litro da solução de nutrientes correspondentes aos diferentes tratamentos encontram-se na Tabela 1.

Procurou-se, também, manter as mesmas concentrações de nutrientes da solução completa nas demais soluções deficientes (veja-se Tabela 1), utilizando outros sais PA.

No caso da solução de sulfato de cálcio, $5 \mathrm{~g}$. deste sal foram diluidos em certo volume de água destilada, com agitação constante. A seguir filtrou-se essa solução e determinou-se o cálcio pelo método complexo-métrico do EDTA. 
Na solução de micronutrientes para o tratamento com omissão da enxofre, o sulfato de zinco e o sulfato de cobre foram substituídos pelo nitrato de zinco, e pelo cloreto de cobre.

Os valores de $\mathrm{pH}$ das soluções de nutrientes eram ajustados com o auxílio de um potenciômetro da BECKMAN entre 6,0 a 6,6, mediante a adição de uma solução de $\mathrm{NaOH} 0,1 \mathrm{~N}$. Os tratamentos que necessitavam de ajuste do $\mathrm{pH}$ receberam entre 2,5 a 3,0 ml daquela solução de hidróxido de sódio por litro de solução e nutriente (veja-se a Tabela 1).

Os valores $\mathrm{pH}$ das soluções originais e das soluções nas quais foram feitas o ajuste, encontram-se na Tabela 2).

Todas as soluções de nutrientes eram trocadas em intervalos de cinco dias até o fim do experimento.

TABELA 2 - Valores pH das soluções de nutrientes:

\begin{tabular}{c|c|c}
\hline tratamentos & valor pH original & valor $\mathrm{pH}$ ajustado \\
\hline \hline Completa & 4,9 & 6,1 \\
$-\mathrm{N}$ & 6,6 & 6,6 \\
$-\mathrm{P}$ & 6,1 & 6,1 \\
$-\mathrm{K}$ & 4,9 & 6,1 \\
$-\mathrm{Ca}$ & 4,8 & 6,1 \\
$-\mathrm{Mg}$ & 5,4 & 6,0 \\
$-\mathrm{S}$ & 6,5 & 6,5 \\
$-\mathrm{Fe}$ & 4,9 & 6,1 \\
\hline
\end{tabular}

\section{Sintomas de Deficiência}

$\mathrm{Na}$ descrição morfológica dos sintomas de deficiência utilizou-se a anotação preconizada, no Atlas de Cores de VILLALOBOS-DOMINGUEZ e VILLALOBOS, 1947. Nesta anotação, a letra ou letras indicam a cor e seu matiz, o número ou números dão o valor da luminosidade, ou seja distinguem os matizes pelo fato de serem mais ou menos claros, ou mais ou menos escuros, e, finalmente, o grau expressa a tonalidade do matiz (NEPTUNE MENARD, 1956).

\section{Cuidados Fitossanitários}

Para se combater o inesperado ataque de ácaros vermelhos (Tetranychus telarius L.) que se iniciou em 12 de agosto de 1969, foram feitas duas pulverizações : a primeira com uma solução de Karathane a $0,3 \%$ no dia 21 de agosto de 1969 e outra, com Metasystox a 0,1\%, no dia 5 de outubro de 1969. 


\section{Medições de Altura, Diametro do Caule e Comprimento do Centro do Limbo da Folha até a Ponta do Lobo do Mesmo}

Um dia antes da colheita, procedeu-se às medições de altura as quais eram tomadas a partir do solo até a gema terminal.

Quando da medição do diametro do caule, ela foi tomada a $5 \mathrm{~cm}$ do solo das plantas.

Como característica indicando o crescimento da planta, achou-se conveniente medir o comprimento do lobo central; esta medição foi efetuada partindo do centro do limbo foliar até o ponto terminal do lóbulo central, como se pode verificar na Figura 1.

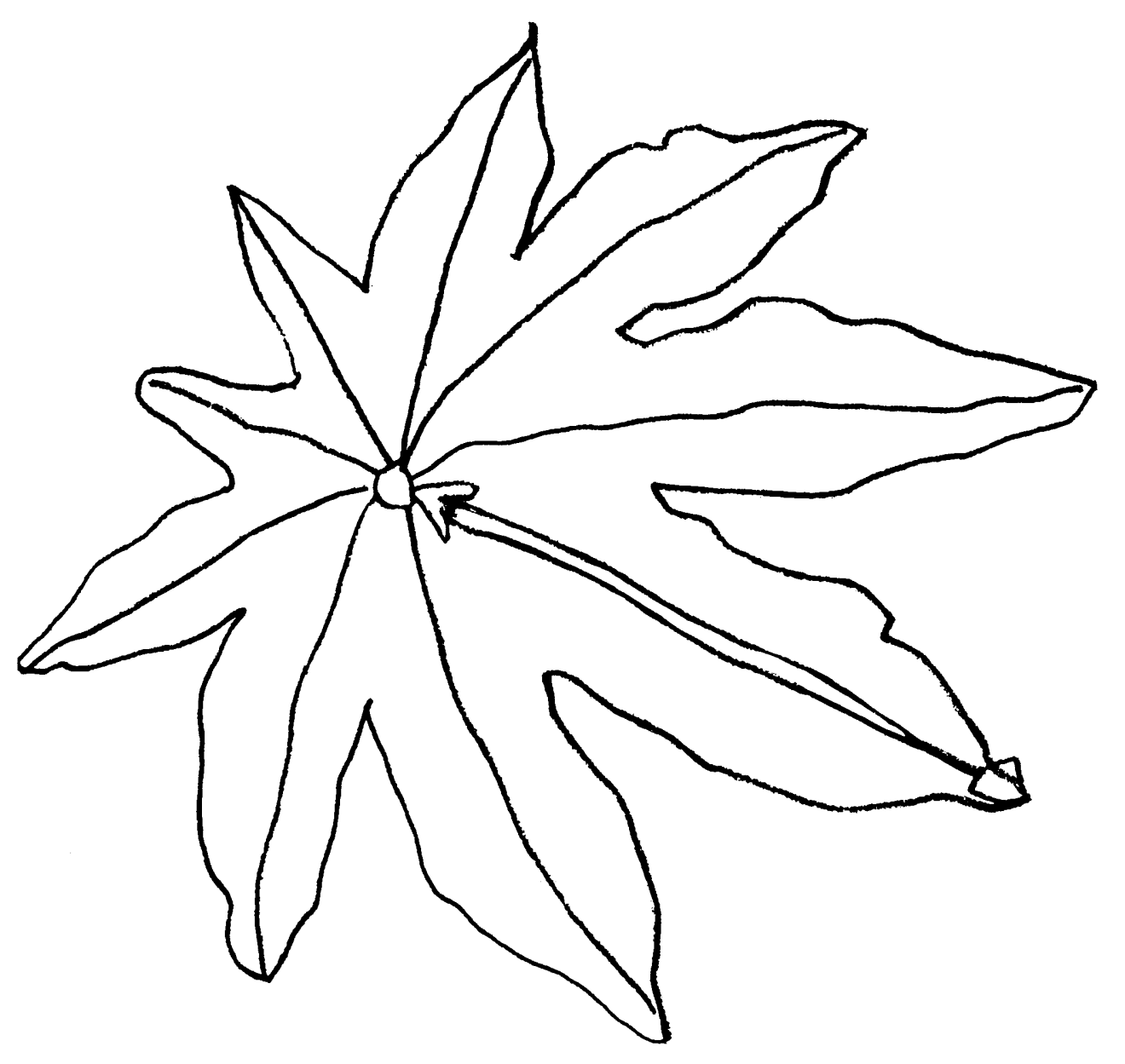

Fig. 1 - Fôlha da mamoneira mostrando o comprimento do lobo central do limbo

\section{Colheita}

Marcas haviam sido feitas, com barbante, abaixo da gema terminal, para na época da retirada das plantas, separar as partes novas das partes velhas. Quando as plantas de determinados tratamentos com omissão de nutrientes mostravam sintomas de deficiencia bastante avançados, estas eram retiradas junto com os respectivos tratamentos das soluções completas de nutrientes. 
A raiz, uma vez separada da planta, foi enxaguada com água desmineralizada, a fim de eliminar o acúmulo de sais e pedacinhos de sílica; a seguir foi lavado com uma solução de HC1 $0,1 \mathrm{~N}$ e lavada novamente com água desmineralizada e enxugada com papel de filtro.

\section{Peso dos limbos das folhas das plantas}

Após cinco dias de permanencia na estufa, as frações das plantas dos diferentes tratamentos foram pesadas em Balança METLER.

\section{Preparação para as Análises Químicas}

$\mathrm{O}$ material colhido, sêco em estufa a $70^{\circ} \mathrm{C}$, pesado, foi moido em micro-moinho Wiley, com força motriz 1/4 HP, modelo $5 \mathrm{KH} 33$ G 106 de 1.725 r.p.m., com peneira de malha n. ${ }^{\circ} 20$. Sobre $0,100 \mathrm{~g}$ de material vegetal, determinou-se o nitrogenio total e sobre $1 \mathrm{~g}$ de material vegetal, preparou-se extratos nitro-percloricos, segundo a técnica descrita por LOTT et al., 1956.

\section{Análises Químicas}

O nitrogenio total foi determinado pelo método de micro Kielcahl, descrito em MALAVOLTA, 1964. Sobre partes aliquotas dos extratos nitro-perclóricos, determinou-se o fósforo pelo método de metavanadato utilizando o fotocolorímetro Klett-Summerson, segundo a técnica descrita em LOTT et al., 1956; o potássio, o cálcio e o magnésio pelo método espectrofotométrico de absorção atomica Perkin-Elmer, modelo 303 de acordo com as instruções do Manual que acompanha o aparelho. $\mathrm{O}$ enxofre foi determinado por gravimetria, seguindo a técnica descrita em MALAVOLTA, 1964.

\section{Análise Estatística}

A análise estatística dos dados foi feita de acôrdo com PIMENTEL GOMES, 1966; STEEL \& TORRIE, 1960.

Como os tratamentos não foram colhidos todos ao mesmo tempo e foram divididos em tres grupos, tornou-se necessário fazer o teste de homogeneidade de variancias, segundo BARTLETT, 1937, citado por PEARSON HARTLEY, 1956. Quando o teste de $\mathrm{X}^{2}$ dá um valor inferior a 5,99, aceita-se a hipótese de que as variâncias, $\mathrm{s}_{1}^{2} \quad \mathrm{~s}_{2}^{2}$ e $\mathrm{s}_{3}^{2}$ estimam uma mesma variancia ${ }^{2}$. Neste caso, podem ser reunidos os tres grupos em um único grupo. 


\section{RESULTADOS E DISCUSSÃO}

\section{Sintomas de Deficiências}

* Os sintomas de deficiência não apareceram todos na mesma época para os diversos tratamentos. Estes começaram a se manifestar um mes e meio após o fornecimento das soluções deficientes. As primeiras manifestações de deficiência apareceram na seguinte ordem de tratamentos: $-\mathrm{N},-\mathrm{Ca},-\mathrm{P},-\mathrm{Mg},-\mathrm{Fe}$ e finalmente $-\mathrm{K}$ e $-\mathrm{S}$.

\section{Tratamento com Omissão de Nitrogenio ( $-\mathrm{N}$ )}

Inicialmente observou-se uma diminuição no crescimento das plantas. As folhas apresentaram uma coloração verde clara (L/10\%/10), pequenas e pecíolos curtos e finos. A nervura principal caracterizava-se por uma coloração branca $\left(\mathrm{L} / 5^{\circ} / 16\right)$ e muito sobressaliente, enquanto que as nervuras secundárias mostravam uma cor verdeamarela (L/9\%/12). A medida que os sintomas iam-se acentuando,

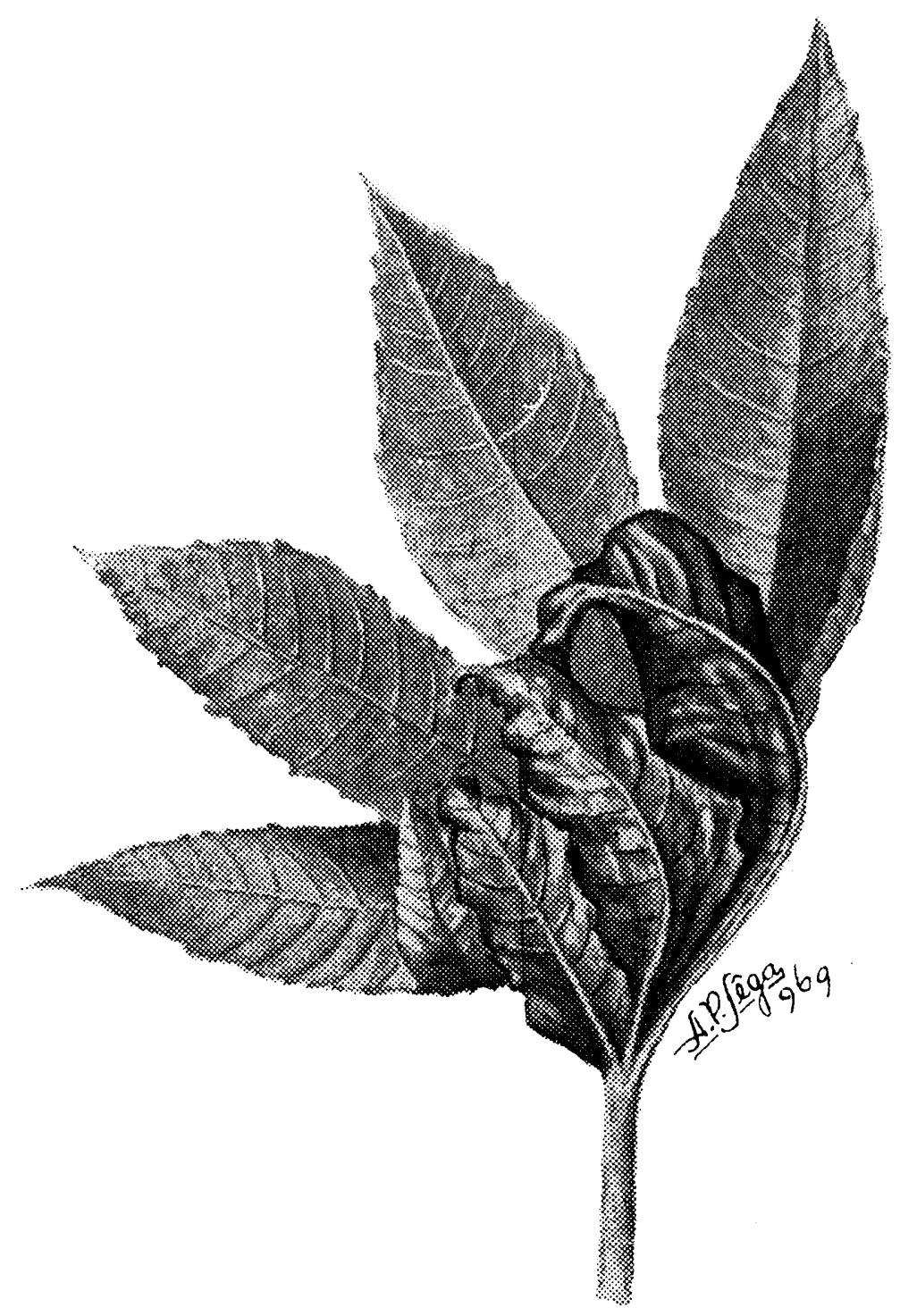

Fig. 2 - Fôlha de mamoeira deficiente em nitrogênio 
as folhas mais maduras começaram a mostrar manchas amarelas, as quais iam-se alargando, até se tornar completamente amarelas (YY/10\%/15). Neste momento, os pecíolos apresentavam uma cor rósea esbranquiçada $\left(\mathrm{MM} / 8^{\circ} / 18\right)$, dobrando-se para baixo. Sintomas iguais foram encontrados por TUCKER, 1952. Antes de secar-se totalmente, a folha se desprendia e caía. Isso é uma indicação de que as folhas velhas cederam o seu nitrogenio para as folhas novas. A intensidade de queda das folhas tornava-se maior com o aparecimento de folhas novas.

Finalmente a parte inferior ficou quase sem fôlhas. $O$ cacho floral era de tamanno reduzido e com muito poucas sementes, o que concorda com as observações de TUCKER, 1952.

\section{Tratamento com Omissão de Fósforo ( $-\mathrm{P})$}

A côr das folhas novas apresentou-se verde-escura bronzeada $\left(\mathrm{LLY} / 11^{\circ} / 6\right)$. Igual observação foi feita por TUCKER. Nas folhas

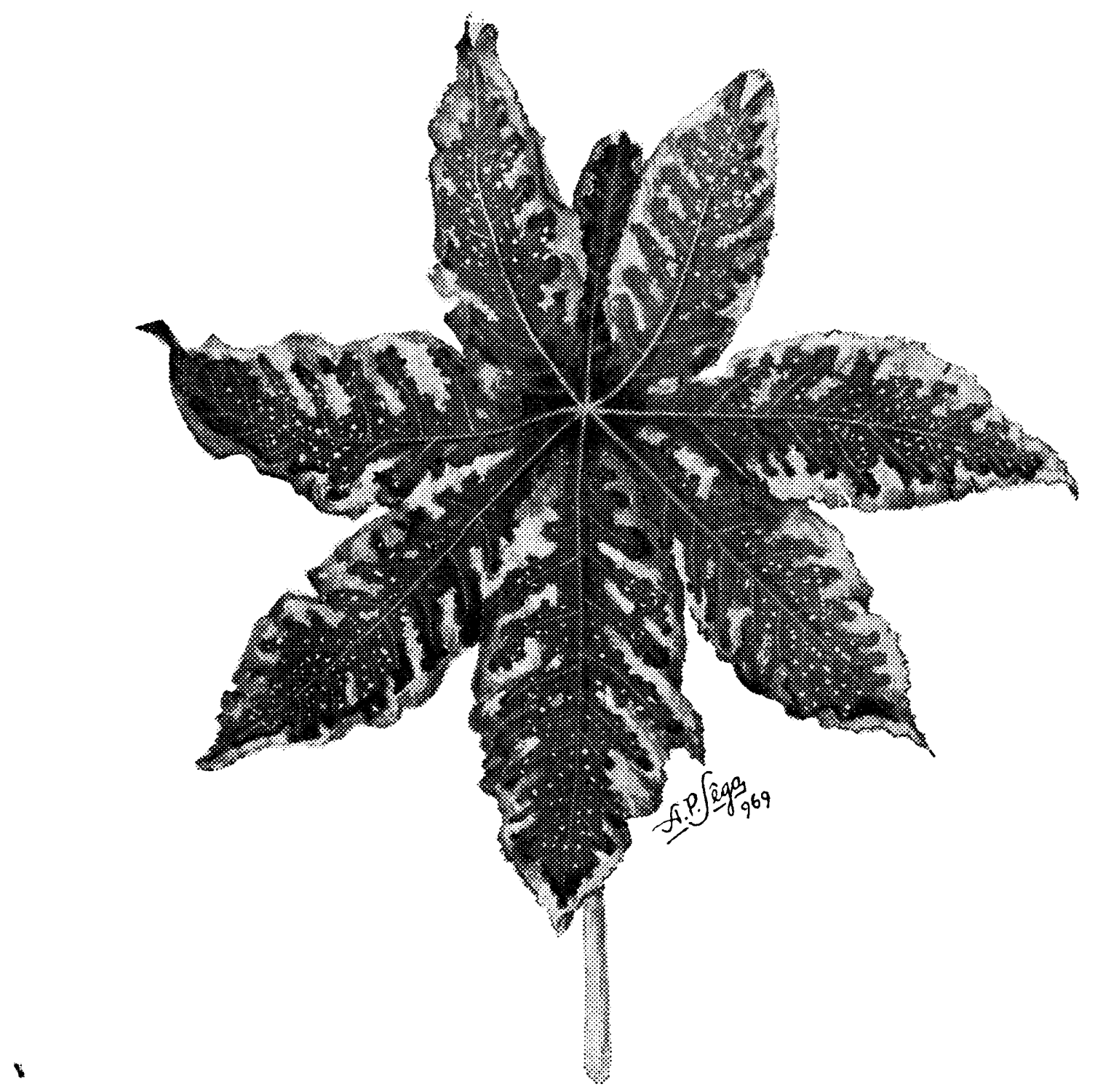

Fig. 3 - Fôlhas de mamoeira deficiente em fósforo 
velhas, os sintomas manifestaram-se, inicialmente, por uma coloração bronzeada $\left(004 / 5^{\circ} / 13\right)$, a qual avançou desde os bordos em direção à parte central da folha e de forma irregular e estendem-se pela zona adjacente às nervuras secundárias, ficando-se a parte central com uma coloração verde escura bronzeada (LLY/11\%/6). A seguir, foram aparecendo pequenas pontuações de coloração brancoamarela repartidas ao acaso. Não foi encontrada nenhuma coloração especial na página inferior do limbo, como foi descrito por TUCKER.

As folhas velhas cairam antes de se secar e conservaram a sua coloração típica mesmo depois de secas em estufa.

Os pecíolos estavam dirigidos para baixo, tal como observara TUCKER. A cor dos mesmos era verde-azulada.

Finalmente a planta ficou com folhas apenas na parte superior ou seja com folhas novas.

O tamanho dos frutos era pequeno, correspondendo à metade do fruto da planta que recebeu a solução completa de nutrientes. 


\section{Tratamento com Omissão de Potássio ( $-\mathrm{K}$ )}

A deficiencia de potássio começou apresentando uma cor verde clara nas pontas dos lóbulos e das margens das folhas maduras. A descoloração foi avançando para o centro do limbo; a seguir apareceram umas raias amarelas colocadas umas ao lado das outras. O resto do limbo mostrou uma coloração verde-amarela (LLY/10\%/10). A medida que se acentou a falta de potássio, as folhas tornaram-se cloróticas (LLY/11\%/11). As margens das mesmas apresentaram-se com manchas necróticas $\left(\mathrm{OY} / 9^{\circ} / 11\right)$. A medida que as folhas ficaram secas, iam-se dobrando para cima.

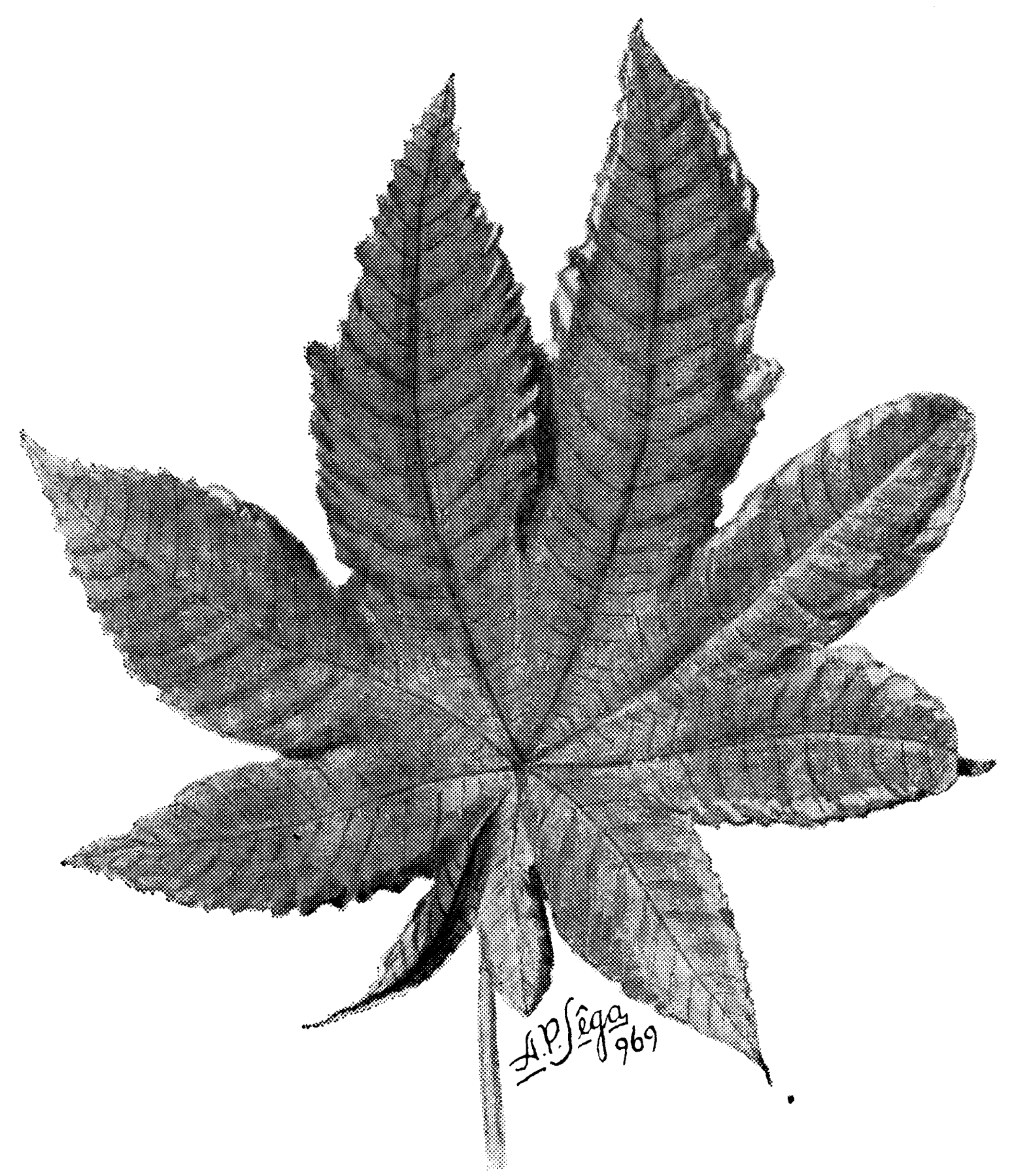

Fig. 4 - Fôlha de mamoeira deficiente em potássio 


\section{Tratamento com Omissão de Cálcio ( $-\mathrm{Ca}$ )}

A carencia de cálcio na planta pode ser observada tanto nas folhas velhas como nas folhas novas. Estas últimas apresentaram-se deformadas, enrugadas. A parte do limbo que fica entre as nervuras secundárias mostrou uma coloração amarela transparente.

Nas folhas maduras, houve uma descoloração das mesmas, tomando uma cor verde-amarela $\left(\mathrm{LLY} / 8^{\circ} / 10\right)$; os lobos ficaram mais próximos e apareceram manchas de cor marrom (OOY/6\%/16). Entre as nervuras secundárias e terciárias manteve-se a coloração verde

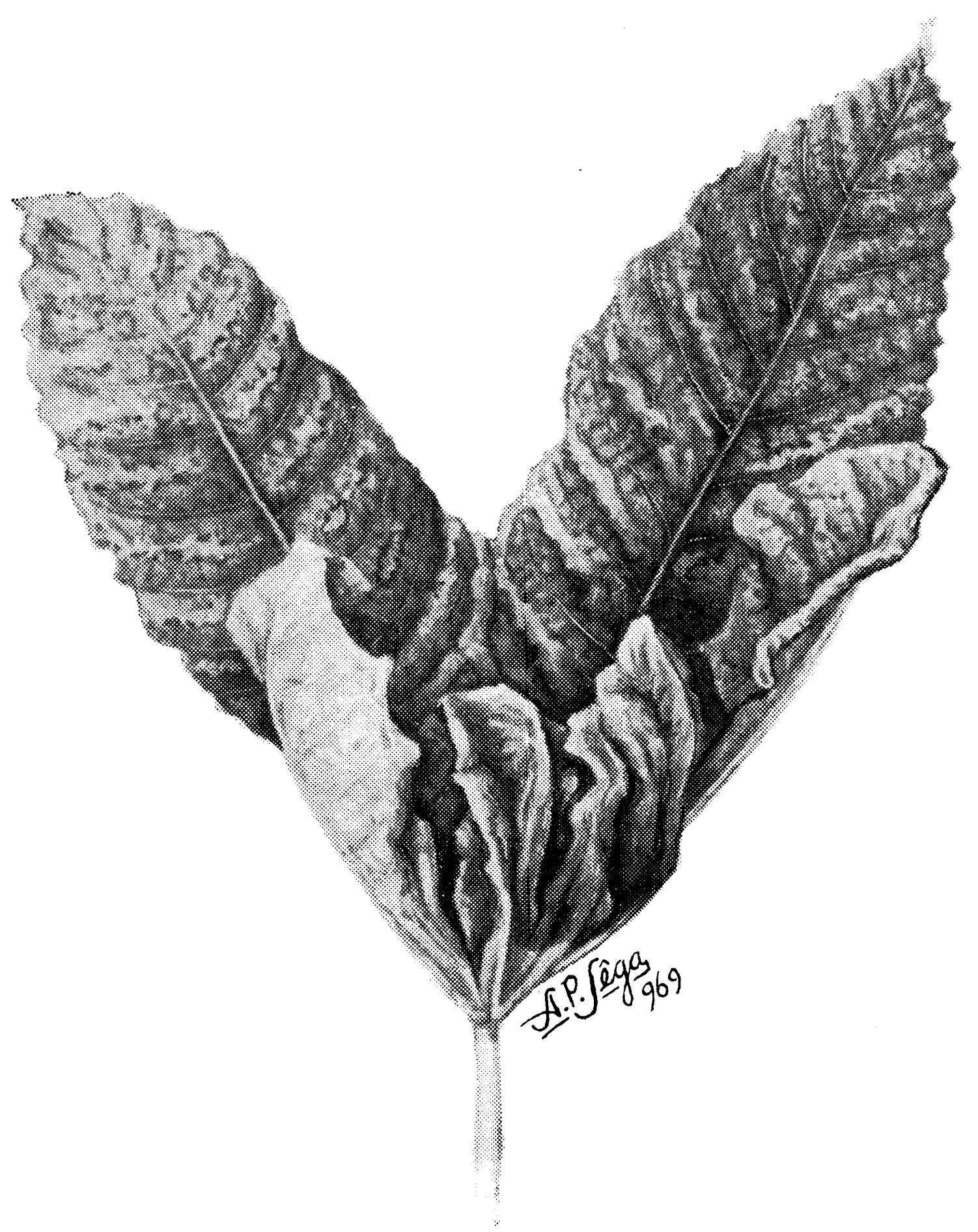

Fig. 5 - Fôlhas de mamoeira deficiente em cálcio 
$\left(\mathrm{L} / 11^{\circ} / 6\right)$. A deficiencia avançou pela porção do limbo entre as nervuras secundárias desde os bordos da folha até a nervura principal do lobo. Os lóbulos começaram a secar-se dobrando para dentro.

As fôlhas terminais apresentaram-se com os lobos bastante fechados e começaram a necrosar-se pelas margens. As plantas perderam suas gemas apicais. Os frutos eram de tamanho reduzido.

As raízes das plantas eram sãs, o que não concorda com a descrição de TUCKER, 1952.

\section{Tratamento com Omissão de Magnésio $(-\mathrm{Mg})$}

Os sintomas apresentaram-se de várias formas. Nas folhas maduras, apareceram um amarelecimento $\left(\mathrm{Y} / 11^{\circ} / 14\right)$ desde a margem das mesmas até o centro do limbo e deixando zonas isoladas de côr vermelha (LLY/11\%/6). Posteriormente desapareceram estas ilhas verdes, deixando nos seus lugares uma coloração amarela (YO/11\%/12), e manchas necróticas de cor marrom escuro $\left(\mathrm{O} / 6^{\circ} / 9\right)$ e marrom claro $\left(\mathrm{Y} / 6^{\circ} / 16\right)$. A coloração verde persistiu ainda na zona adjacente

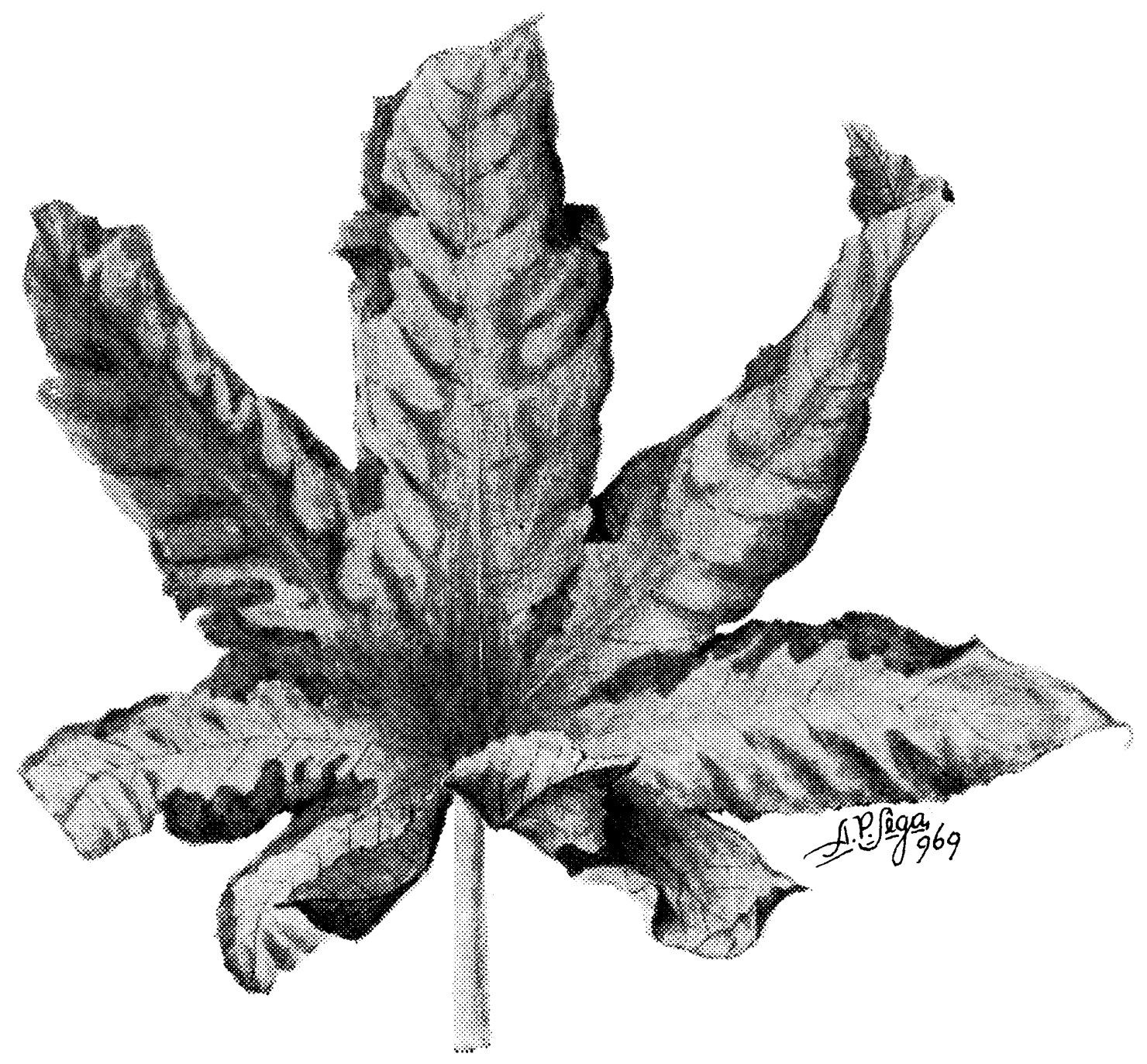

Fig. 6 - Fôlhas de mamoeira deficiente em magnésio 
às nervuras principais e, em ambos os lados das nervuras secundá. rias, as margens das folhas já secas, torceram-se para baixo na forma da letra ", enquanto que os lóbulos dobraram as suas pontas para cima.

Observou-se também um amarelecimento de toda a porção do limbo entre as nervuras secundárias, ficando uma faixa verde $\left(\mathrm{L} / 11^{\circ} / 11\right)$ perto das nervuras principais e secundárias.

Deu-se uma clorose e uma necrose nas margens, as quais estenderam-se até os pecíolos. Os frutos não alcançaram o seu tamanho normal, porém, para Tucker, nas plantas deficientes em magnésio, não se formaram frutos.

\section{Tratamento com Omissão de Enxofre ( $-\mathbf{S})$}

Os sintomas de deficiencia de enxofre apareceram por último.

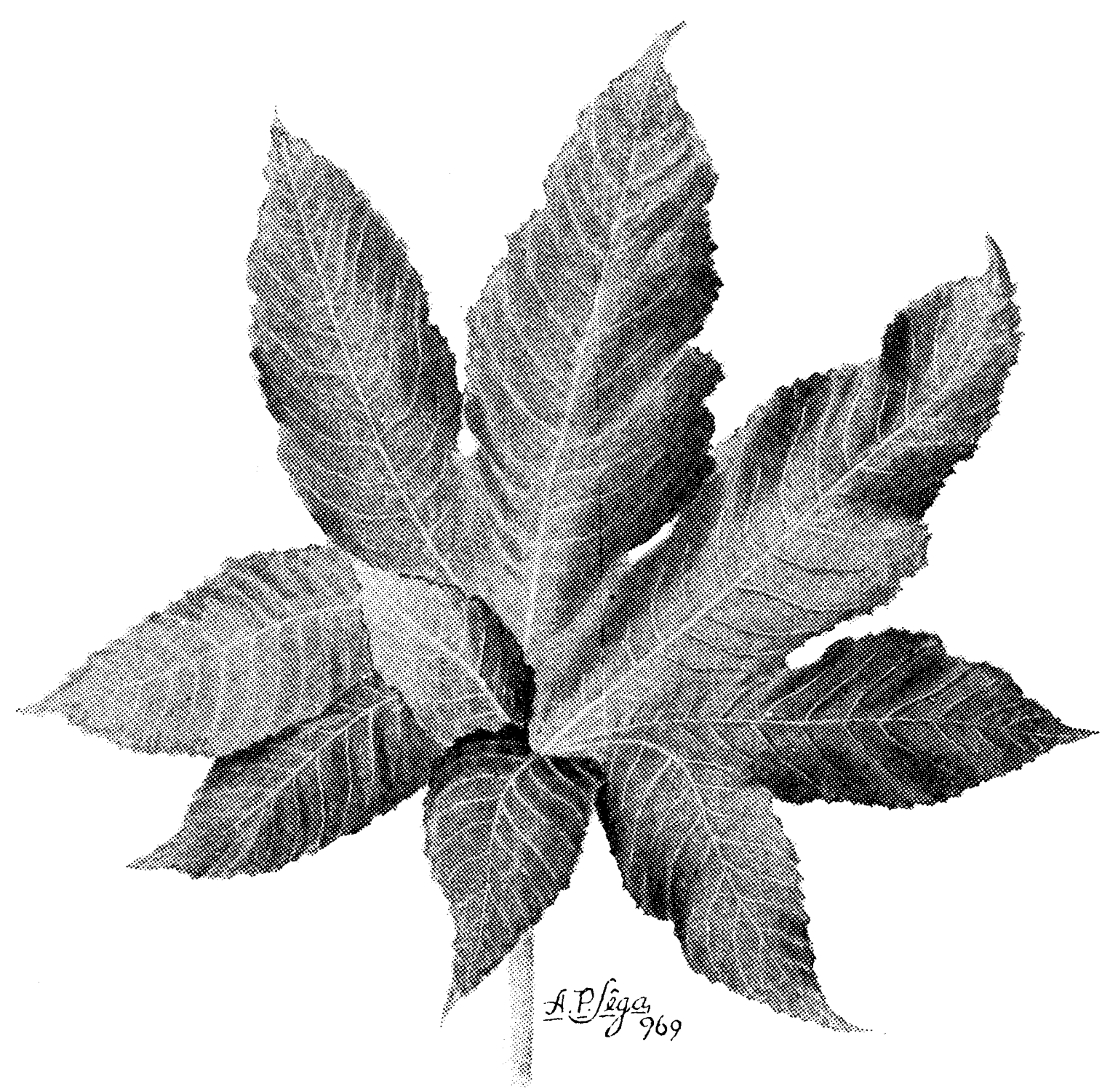

Fig. 7 - Fôlhas de mamoeira deficiente em enxôfre 
As folhas mostraram-se bem desenvolvidas, de tamanho ligeiramente inferior àquelas das plantas do tratamento completo.

O primeiro sintoma que se observou foi uma coloração verdelimão $(\mathrm{L} / \mathrm{o} / 11)$. As nervuras secundárias apresentaram uma côr verde clara $\left(1 / 5^{\circ} / 12\right)$. Os lobos fecharam-se até adquirir uma forma parecida com uma taça. Os pecíolos eram normais. A medida que se acentuavam a deficiência, as folhas mostraram uma coloração amarela levemente bronzeada $\left(\mathrm{YYO} / 12^{\circ} / 15\right)$ e pequenas manchas necróticas entre as nervuras secundárias e necrose nos bordos das folhas.

Verificou-se também pontos necróticos ao longo da nervura principal. Houve algumas folhas com pontos esbranquiçados ( $\left.\mathrm{YYO} / 2^{\mathrm{a}} / 17\right)$ disseminados no limbo, e maior acumulação destes pontos na extremidade do limbo perto das nervuras secundárias.

\section{Tratamento com Omissão de Ferro $(-\mathrm{Fe})$}

Os sintomas de deficiencia de ferro iniciaram-se nas folhas novas, as quais tomaram uma coloração verde-amarela ligeiramente dourada ( $\left.\mathrm{L} / 10^{\circ} / 14\right)$, com as nervuras secundárias e zonas adjacentes de coloração verde-escura $\left(\mathrm{L} / 11^{\circ} / 8\right)$. A coloração da nervura principal foi de um verde mais claro $\left(\mathrm{L} / 10^{\circ} / 13\right)$.

As folhas bem novas que mostraram estes sintomas não se desenvolveram, necrosaram-se e cairam. Estes sintomas foram também observados por TUCKER.

Observou-se também, na mesma planta, folhas maduras com desenvolvimento normal e verdes $\left(\mathrm{L} / 10^{\circ} / 6\right)$ e folhas maduras de cor verde-amarela ( $\left.\mathrm{LLY} / 5^{\circ} / 14\right)$. Ainda mais, apareceram folhas normais com manchas necróticas disseminadas no limbo. Estes sintomas foram observados também por TUCKER.

As plantas com deficiencia de ferro não perderam muitas folhas como nos outros tratamentos. 


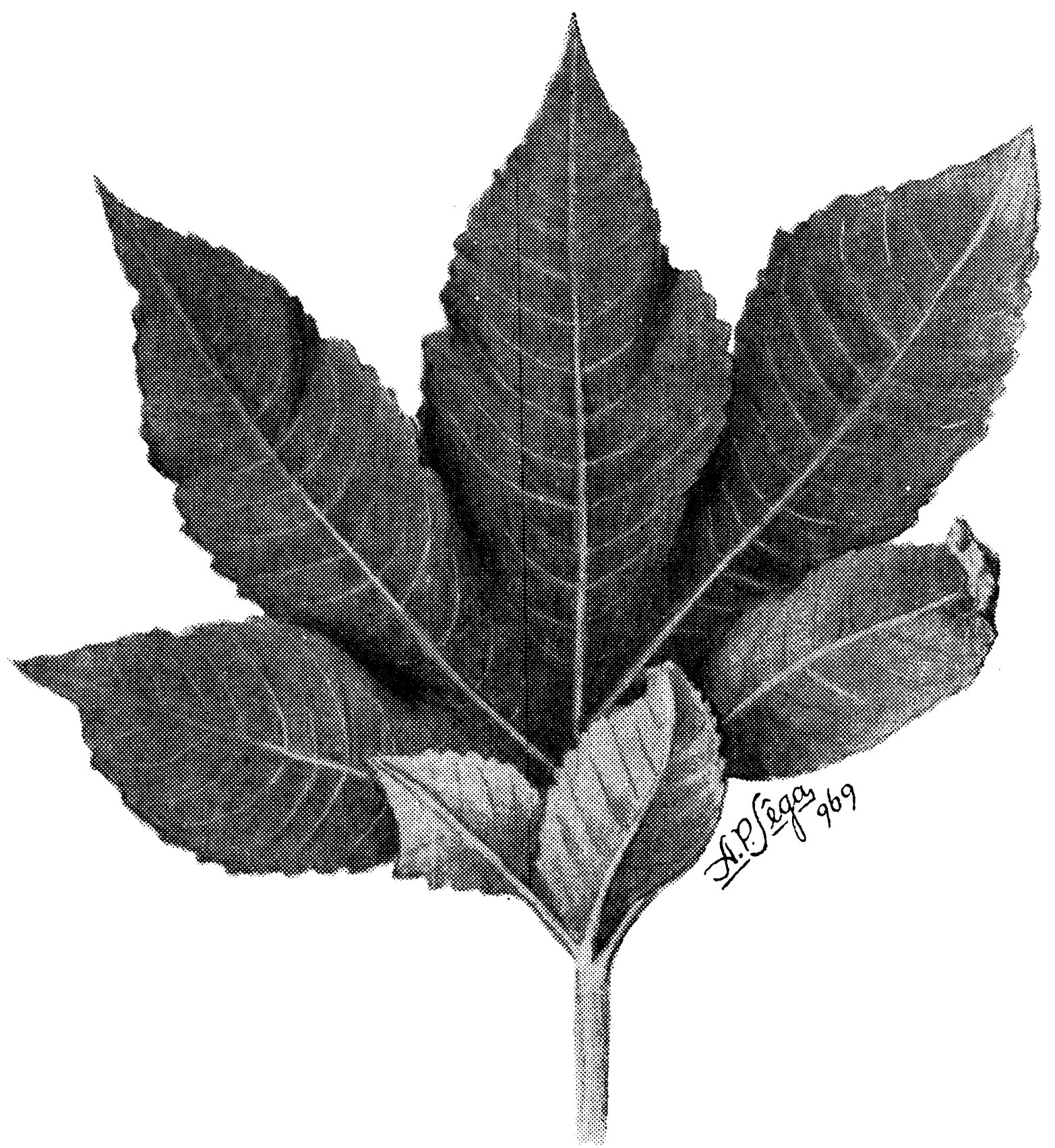

Fig. 8 - Fôlha de mamoeira deficiente em ferro

Tratamento completo, com presença de todos os nutrientes

As plantas apresentaram-se com folhas bem desenvolvidas; o limbo mostrou uma coloração verde opaca $\left(\mathrm{L} / 12^{\circ} / 5\right)$. As nervuras principais eram verde-amarelas $\left(\mathrm{L} / 7^{\circ} / 12\right)$ e as secundárias amarelaverdes $\left(\mathrm{L} / 9^{\circ} / 12\right)$.

As folhas eram suaves ao tacto e quando maduras, descolorava-se o limbo tornando-se amarelo; ao secar, os bordos do limbo e os pequenos lobos fecharam-se para cima e para o centro da lamina. 
As plantas não perderam muitas folhas quando comparadas com aquelas dos outros tratamentos.

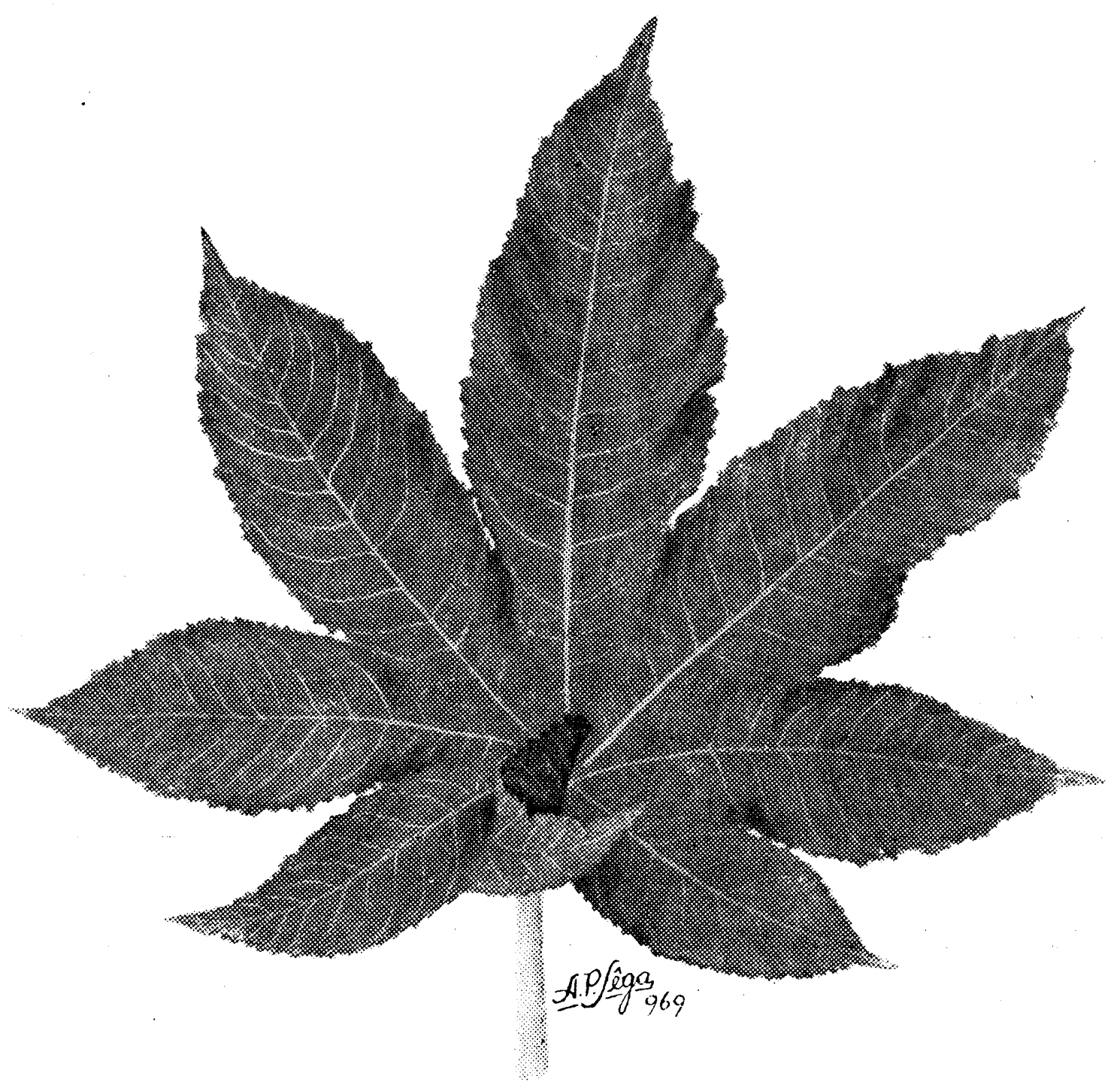

Fig. 9 - Fôlha de mamoeira normal

\section{Crescimento}

O crescimento das plantas foi avaliado através das medições de altura, de diametro do caule, do comprimento do lobo central do limbo da folha da planta inteira.

\section{Altura das Plantas}

As alturas médias das plantas de cada tratamento, expressas em centímetros, encontram-se na Tabela 3. 
TABELA 3 - Altura inicial e final das plantas em $\mathrm{cm}$.

\begin{tabular}{c|cc}
\hline tratamentos & altura inicial & altura final \\
\hline$-\mathrm{N}$ & 43,33 & 16,30 \\
$-\mathrm{P}$ & 49,30 & 16,20 \\
$-\mathrm{K}$ & 62,00 & 16,40 \\
$-\mathrm{Ca}$ & 62,00 & 16,30 \\
$-\mathrm{Mg}$ & 49,00 & 16,20 \\
$-\mathrm{S}$ & 62,00 & 16,20 \\
$-\mathrm{Fe}$ & 59,00 & 16,20 \\
$\mathrm{C}_{11}$ &.-- &.-- \\
$\mathrm{C}_{22}$ &.-- &.-- \\
$\mathrm{C}_{33}$ &.-- &.-- \\
$\mathrm{C}$ & 67,08 & 16,10 \\
\hline
\end{tabular}

d. m. s. ao nível de $5 \%=17,91$ (Dunnett)

d. m. s. ao nível de $1 \%=24,99$ (Tuckey)

C.V. $=15,98$

A média dos tratamentos sendo inferior a média do teste de homogeneidade $\left(X^{2}=5,99\right)$ permite fazer a análise estatística em conjunto.

As plantas do tratamento completo, pelo teste de Dunnett eram somente mais altas que aquelas dos tratamentos com omissão de nitrogenio, fósforo e magnésio. Comparando os tratamentos com omissão dos nutrientes não houve efeito significativo pelo teste de Tuckey. Apesar de não ter havido diferença estatística entre os tratamentos as alturas das plantas deficientes em $\mathrm{K}, \mathrm{Ca}, \mathrm{S}$ e $\mathrm{Fe}$ aproximam-se muito mais das alturas das plantas do tratamento completo. As plantas dos tratamentos com carencia de nitrogenio, fósforo $\mathrm{e}$ magnésio mostraram alturas menores.

\section{Diâmetro da Base do Caule}

O diâmetro médio da base; do caule, expresso em $\mathrm{mm}$ para as plantas de cada tratamento, encontra-se na Tabela 4. 
TABELA 4 - Diâmetro da base do caule em mm.

\begin{tabular}{|c|c|c|c|}
\hline tratamentos & $\begin{array}{c}\text { diâmetro } \\
\text { inicial }\end{array}$ & $\begin{array}{l}\text { diâmetro } \\
\text { final }\end{array}$ & \\
\hline \multicolumn{4}{|l|}{ 1. Grupo } \\
\hline$-\mathbf{N}$ & 3,10 & 13,0 & \multirow{5}{*}{$\begin{array}{l}\text { Teste Dunnett }(5 \%)= \\
\quad 2,17 \\
\text { C. V. }=16,98 \\
\text { Teste Tuckey }(5 \%)= \\
\quad 4,07\end{array}$} \\
\hline$-P$ & 3,20 & 16,0 & \\
\hline$-\mathrm{Ca}$ & 3,16 & 16,0 & \\
\hline$-\mathrm{Mg}$ & 3,16 & 15,0 & \\
\hline $\mathbf{C}_{1}$ & 3,20 & 18,3 & \\
\hline \multicolumn{3}{|l|}{ 2. Grupo } & \multirow[t]{2}{*}{ Teste Dunnett $(5 \%)=$} \\
\hline$-\mathrm{Fe}$ & 3,10 & 18,7 & \\
\hline \multirow[t]{2}{*}{$\mathbf{C}_{2}$} & 3,10 & 18,0 & $\begin{array}{l}\quad 6,49 \\
\text { C. } \mathrm{v} . \\
=18,08\end{array}$ \\
\hline & & & Teste Dunnett $(5 \%)=$ \\
\hline \multicolumn{4}{|l|}{ 3. Grupo } \\
\hline$-\mathrm{K}$ & 3,20 & 14,7 & \multirow{3}{*}{ Teste $\begin{array}{c}1,47 \\
1,35\end{array}$} \\
\hline$-\mathbf{S}$ & 3,10 & 16,0 & \\
\hline $\mathrm{C}_{3}$ & 3,20 & 18,3 & \\
\hline & & & C- V. $=4,23$ \\
\hline
\end{tabular}

A análise estatística foi feita por grupos devido a que a média dos tratamentos foi superior ao teste de homogeneidade $\left(\mathrm{X}^{2}=5,99\right)$.

Comparando os tratamentos dos tres grupos com os tratamentos completos respectivos, houve efeito significativo pelo teste de Dunnett ou seja o diâmetro médio do caule dos tratamentos foi maior que o dos outros tratamentos.

Apesar de não haver significancia estatística entre os tratamentos dos diferentes grupos, é interessante observar que as plantas deficientes em nitrogenio apresentam diametro menor, a seguir aquelas deficientes em potássio e magnésio, depois daquelas deficientes em fósforo, cálcio e enxofre.

\section{Comprimento do Centro do Limbo da Folha até a Ponta do Lobo Central}

Os dados sobre o comprimento médio do centro do limbo até a ponta do lobo central expressos em $\mathrm{cm}$, encontram-se na Tabela 5. 
TABELA 5 - Comprimento em $\mathrm{cm}$ do centro do limbo da folha até a ponta do lobo central

\begin{tabular}{c|c}
\hline tratamentos & comprimento \\
\hline$-\mathrm{N}$ & 13,50 \\
$-\mathrm{P}$ & 18,00 \\
$-\mathrm{K}$ & 17,47 \\
$-\mathrm{Ca}$ & 19,00 \\
$-\mathrm{Mg}$ & 20,00 \\
$-\mathrm{S}$ & 18,66 \\
$-\mathrm{Fe}$ & 20,30 \\
$\mathrm{C}$ & 21,95 \\
Teste de Dunnett $(5 \%)-4,44$ \\
Teste de Tuckey $(5 \%)=7,90$ \\
C.V. & $=$ \\
\hline
\end{tabular}

Comparando, pelo teste de Dunnett os tratamentos deficientes e o completo, houve efeito significativo apenas entre os tratamentos - $\mathrm{N}$ e $-\mathrm{K}$ com o tratamento completo (C). Apesar de que as diferenças entre os tratamentos não foram significativas, notou-se uma grande diferença entre o tratamento $-\mathrm{N}$ e os outros.

\section{Peso em gramas (g) da planta e dos limbos das folhas nos diferentes tratamentos}

\section{Peso do limbo das folhas velhas}

O teste de Dunnett não permitiu estabelecer diferença estatisticamente significativa entre o limbo das folhas velhas do tratamento completo com aquele dos outros tratamentos. Tampouco, houve diferença estatística entre os tratamentos deficientes em nutrientes. Porém, observou-se uma produção de matéria seca menor nos tratamentos com omissão de nitrogenio, fósforo e potássio.

\section{Peso do limbo das folhas novas}

Apareceu diferença estatisticamente significativa entre os tratamentos completo e com omissão de nitrogenio. Menor peso do limbo das folhas novas foi obtido. Não houve diferença estatisticamente significativa entre os outros tratamentos deficientes e o completo.

Comparando, entre si, o peso do limbo das folhas novas das plantas deficientes, o tratamento com omissão de nitrogenio é inferior aos tratamentos com omissão de cálcio, magnésio, enxofre e ferro, e este último é superior aos tratamentos com omissão de fósforo e cálcio. 


\section{Peso das plantas inteiras}

Comparando o peso das plantas inteiras do tratamento completo e dos tratamentos deficientes em $\mathrm{N}, \mathrm{P}, \mathrm{Ca}$ e $\mathrm{Mg}$, houve diferença significativa a favor do tratamento completo. Não houve diferença estatisticamente significativa entre o peso das plantas inteiras e aquele das plantas deficientes em $\mathrm{K}, \mathrm{S}$ e Fe.

Comparando os tratamentos deficientes entre si, as plantas com omissão de ferro produziam maior quantidade de matéria seca que aquelas com omissão de $\mathrm{N}, \mathrm{P}$ e $\mathrm{Mg}$.

\section{Distribuição Percentual dos Macronutrientes nos limbos das folhas das plantas nos diferentes tratamentos}

Os resultados das análises químicas dos macronutrientes são apresentados nas Tabelas. Os dados foram analisados pelos testes de Dunnett e Tuckey, respectivamente ao nível de 5\%. Os valores obtidos representaram a média de tres repetições para as frações das plantas deficientes e de quatro ou de doze repetições para as frações das plantas não deficientes.

TABELA 6 - Percentagem de nitrogenio nos limbos das folhas das plantas nos diferentes tratamentos

\begin{tabular}{l|c|c|}
\hline \multirow{2}{*}{ tratamentos } & \multicolumn{2}{|c|}{ limbo } \\
\cline { 2 - 3 } & velho & novo \\
\hline \hline & 0,258 & 1,514 \\
$-\mathrm{N}$ & 3,014 & 3,377 \\
$-\mathrm{Ca}$ & 3,080 & 3,338 \\
$-\mathrm{Mg}$ & 2,473 & 3,798 \\
$-\mathrm{Fe}$ & 2,454 & 3,602 \\
$-\mathrm{S}$ & 2,150 & 3,108 \\
$-\mathrm{K}$ & 2,613 & 2,986 \\
\hline & & 2,939 \\
$\mathrm{C}$ & 2,718 & $(0,996)$ \\
Teste Dunnett & $(0,550)$ & $(1,099)$ \\
Teste Tuckey & $(0,607)$ & $(17,34)$ \\
C. V. V. & $(10,96)$ & \\
\hline
\end{tabular}

Distribuição percentual do nitrogenio nos limbos das folhas das plantas nos diferentes tratamentos 


\section{Percentagem de nitrogenio no limbo das folhas}

\section{a) Percentagem de nitrogenio no limbo das folhas velhas}

Houve diferença significativa apenas entre os tratamentos completo e deficientes em enxofre e nitrogenio. Comparando entre si os tratamentos deficientes, os limbos das folhas deficientes em fósforo e cálcio apresentaram maior concentração de nitrogenio.

Não houve diferença significativa entre os tratamentos $-\mathrm{Ca},-\mathrm{P}$ e $-\mathrm{K}$, porém houve diferença significativa entre os tratamentos $-\mathrm{Mg}$, - Fe e - S a favor do tratamento - Ca e a favor do tratamento - P, contra o tratamento $-\mathrm{S}$. O tratamento $-\mathrm{N}$, como é claro, foi inferior a todos os demais.

TABELA 7 - Percentagem de fósforo nos limbos das folhas nos diferentes tratamentos

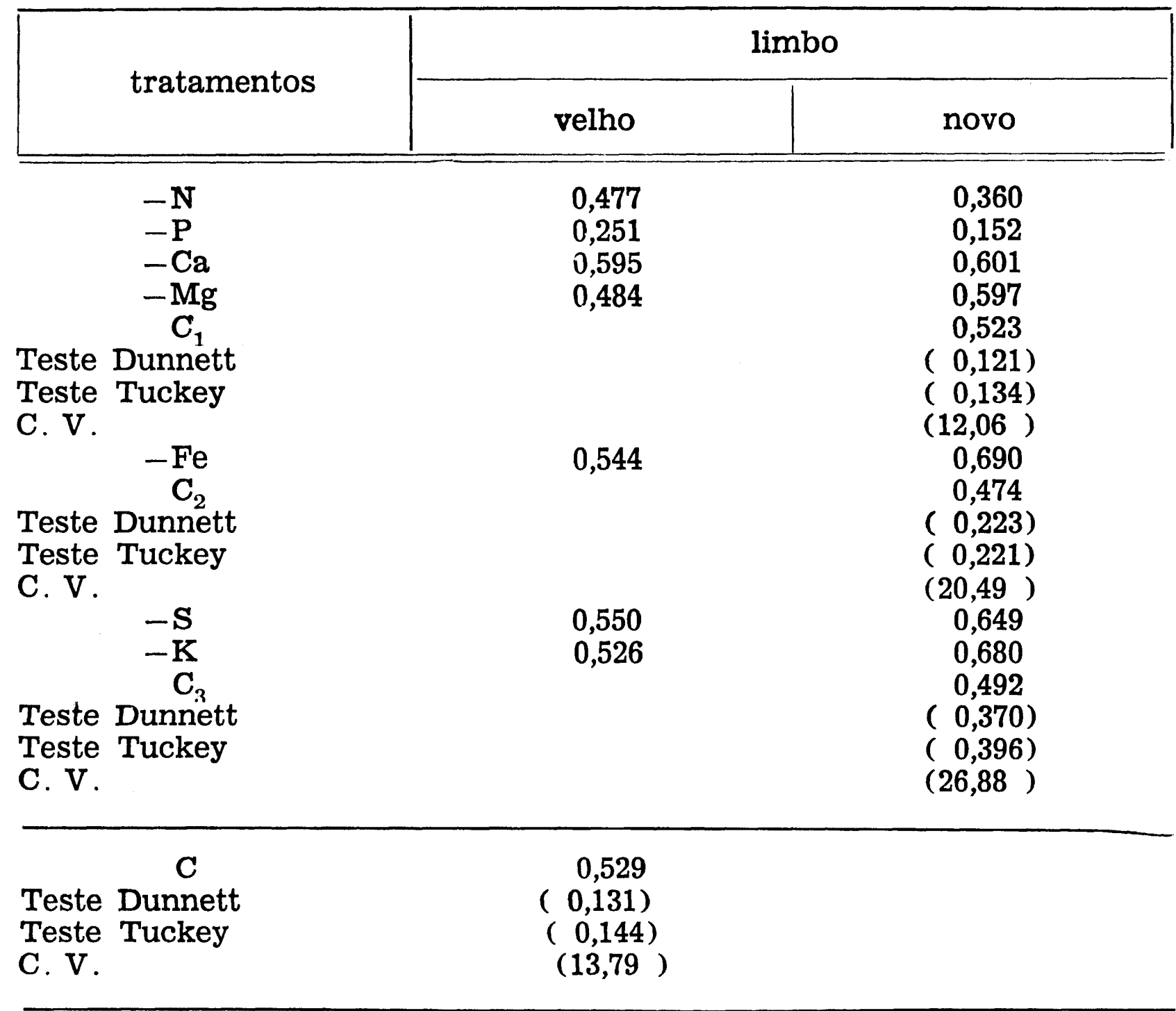

b) Percentagem de nitrogenio no limbo das folhas novas

Comparando o tratamento completo com todos os demais, encontrou-se que o tratamento com omissão de nitrogenio fọi inferior aos demais. 


\section{Distribuição percentual ou concentração do fósforo nos limbos das folhas nos diferentes tratamentos \\ Percentagem de fósforo no limbo}

\section{a) Percentagem de fósforo no limbo velho}

Comparando a percentagem de fósforo no tratamento completo com os tratamentos deficientes, apenas o tratamento com omissão de fósforo apresentou diferença estatística do tratamento completo.

Comparando entre si os tratamentos deficientes, verificou-se que, somente os tratamentos com omissão de fósforo foram estatisticamente diferentes dos outros.

\section{b) Percentagem de fósforo no limbo novo}

Comparando a percentagem de fósforo no tratamento completo com os tratamentos deficientes houve diferença significativa, apenas no primeiro grupo entre os tratamentos com omissões de cálcio. nitrogenio e fósforo, sendo o tratamento com omissão de cálcio o que acusou maior concentração de fósforo.

Embora não haja diferença estatística, os tratamentos que apresentaram maiores concentrações de fósforo são os tratamentos com omissões de $\mathrm{K}, \mathrm{Fe}, \mathrm{S}, \mathrm{Ca}$ e $\mathrm{Mg}$. Isso, talvez, explique que houve uma mobilidade deste elemento para o limbo da folha.

Distribuição percentual ou concentração de potássio nos limbos das folhas nos diferentes tratamentos

TABELA 8 - Percentagem de potássio nos limbos das folhas nos diferentes tratamentos

\begin{tabular}{|c|c|c|c|}
\hline \multirow{2}{*}{\multicolumn{2}{|c|}{ tratamentos }} & \multicolumn{2}{|c|}{ limbos } \\
\hline & & velhos & novos \\
\hline & $\begin{array}{l}-\mathrm{N} \\
-\mathrm{P} \\
-\mathrm{Ca} \\
-\mathrm{Mg} \\
-\mathrm{Fe} \\
-\mathrm{S} \\
-\mathrm{K} \\
-\mathrm{C}\end{array}$ & $\begin{array}{l}3,051 \\
2,749 \\
3,423 \\
3,286 \\
2,873 \\
3,294 \\
1,900 \\
3,316\end{array}$ & $\begin{array}{l}2,030 \\
2,041 \\
3,205 \\
3,268 \\
2,675 \\
2,865 \\
1,086 \\
2,612\end{array}$ \\
\hline $\begin{array}{l}\text { Teste } \\
\text { Teste } \\
\text { C. V. }\end{array}$ & $\begin{array}{l}\text { Dunnett } \\
\text { Tuckey }\end{array}$ & $\begin{array}{l}(0,620) \\
(0,685) \\
(10,69)\end{array}$ & $\begin{array}{l}(1,195) \\
(1,318) \\
(25,23)\end{array}$ \\
\hline
\end{tabular}




\section{Percentagem de potássio no limbo da folha}

a) Percentagem de potássio no limbo velho da folha

Houve diferença significativa apenas entre o tratamento com omissão de potássio e o tratamento completo e a diferença estatística entre aquele tratamento e os demais não foi significativo. A concentração de potássio no limbo velho é de $1,90 \%$ no tratamento deficiente em potássio e de 3,32\% no tratamento completo.

b) Percentagem de potássio no limbo novo da folha

Houve diferença significativa, apenas entre o tratamento com omissão de potássio e o tratamento completo $(1,086 \%$ de $\mathrm{K}$ e $2,612 \%$ de $\mathrm{K}$ respectivamente).

Ao comparar entre si os tratamentos, verificou-se que os tratamentos que não diferem estatisticamente do tratamento deficiente em potássio foram os tratamentos com omissão de nitrogenio e potássio.

Distribuição percentual de cálcio nos limbos das folhas nos diferentes tratamentos

Tabela 9 - Percentagem de cálcio nos limbos nos diferentes tratamentos

\begin{tabular}{|c|cc|}
\hline \multirow{2}{*}{ Tratamentos } & \multicolumn{2}{|c|}{ limbo } \\
\cline { 2 - 3 } & velho & novo \\
\hline$-\mathbf{N}$ & 1,351 & 0,739 \\
$-\mathbf{P}$ & 2,318 & 2,051 \\
$-\mathrm{Ca}$ & 1,014 & 0,228 \\
$-\mathrm{Mg}$ & 2,101 & 1,594 \\
$-\mathrm{Fe}$ & 2,406 & 1,297 \\
$-\mathbf{S}$ & 1,983 & 1,883 \\
$-\mathrm{K}$ & 2,707 & 2,676 \\
\hline $\mathbf{C}$ & 2,099 & 1,466 \\
Teste Dunnett & $(0,713)$ & $(0,824)$ \\
Teste Tuckey & $(0,787)$ & $(0,090)$ \\
C.V & $(18,67)$ & $(29,43)$ \\
\hline
\end{tabular}

Percentagem de cálcio no limbo

\section{a) Percentagem de cálcio no limbo velho}

Comparando o tratamento completo com os tratamentos deficientes, apareceu uma concentração de cálcio estatisticamente maior no tratamento completo do que no tratamento com omissão deste elemento.

Comparando entre si os tratamentos deficientes, não houve diferença estatística entre os tratamentos com omissões de cálcio e de nitrogenio; porém, o tratamento com omissão de ferro foi superior ao tratamento com omissão de nitrogenio. 


\section{b) Percentagem de cálcio no limbo novo}

No confronto do tratamento completo com os tratamentos deficientes, aquele acusou menor percentagem em cálcio do que o tratamento deficiente em potássio e maior percentagem de cálcio do que no tratamento deficiente neste elemento.

Comparando entre si os tratamentos com omissões dos nutrientes todos esses apresentaram maior porcentagem em cálcio do que o tratamento com omissão deste nutriente. Os tratamentos com omissões de $\mathrm{K}, \mathrm{P}$ e $\mathrm{S}$ foram superiores ao tratamento com omissão de nitrogenio. Não houve diferença significativa entre os tratamentos com omissões de $\mathrm{N}^{\prime}$ e $\mathrm{Ca}$ e tampouco entre os tratamentos com omissões de potássio, fósforo e enxofre.

\section{Distribuição percentual de magnésio nos limbos das folhas dos diferentes tratamentos}

Tabela 10 - Percentagem de magnésio nos limbos das folhas nos diferentes tratamentos

\begin{tabular}{|c|c|c|}
\hline \multirow{2}{*}{ Tratamentos } & \multicolumn{2}{|c|}{ limbo } \\
\hline & velho & novo \\
\hline$-\mathbf{N}$ & 0,695 & 0,142 \\
\hline$-P$ & 0,709 & 0,392 \\
\hline$-\mathrm{Ca}$ & 0,942 & 0,744 \\
\hline$-\mathbf{M g}$ & 0,371 & 0,168 \\
\hline $\mathrm{C}_{1}$ & & 0,547 \\
\hline Teste Dunnett & & $(0,180)$ \\
\hline Teste Tuckey & & $(0,200)$ \\
\hline C.V. & & $(17,65)$ \\
\hline$-F e$ & 0,706 & 0,465 \\
\hline $\mathrm{C}_{2}$ & & 0,428 \\
\hline Teste Dunnett & & $(0,172)$ \\
\hline Teste Tuckey & & $(0,171)$ \\
\hline C.V. & & $(19,75)$ \\
\hline$-\mathbf{S}$ & 0,652 & 0,527 \\
\hline$-\mathbf{K}$ & 0,797 & 0,913 \\
\hline $\mathbf{C}_{3}$ & & 0,542 \\
\hline Teste Dunnett & & $(0,560)$ \\
\hline Teste Tuckey & & $(0,599)$ \\
\hline $\mathrm{V}$ & & $(41,08)$ \\
\hline $\mathbf{C}$ & 0,671 & \\
\hline Teste Dunnett & $(0,149)$ & \\
\hline Teste Tuckey & $(0,145)$ & \\
\hline C.V. & $(11,54)$ & \\
\hline
\end{tabular}




\section{Percentagem de magnésio no limbo das folhas}

\section{a) Percentagem de magnésio nos limbos das folhas velhas}

Ao comparar os tratamentos deficientes com o tratamento completo pelo teste de Dunnett ao nível de 5\%, verificou-se que os tratamentos com omissão de cálcio e magnésio apresentavam concentração maior e menor, respectivamente, do que o completo.

Comparando os tratamentos entre si pelo teste de Tuckey ao nível de 5\%, constatou-se que todos apresentavam teor em magnésio superior ao tratamento em que foi omitido esse elemento, e também que o tratamento com omissão de cálcio apresentava superioridade em teor de magnésio sobre todos os demais tratamentos.

De maneira geral a percentagem de magnésio em folhas velhas é aproximadamente daquela encontrada no pecíolo velho e a variação entre um tratamento e outro é pequena. Pode-se dizer que a distribuição é mais uniforme nos diferentes tratamentos que nas outras frações da planta.

\section{b) Percentagem de magnésio no limbo das folhas novas}

A análise estatística desta fração foi feita por grupos de tratamentos. Pelo teste de Dunnett apenas no primeiro grupo houve diferença estatística significativa. O tratamento com omissão de cálcio apresentou concentração de magnésio superior ao do tratamento completo e os tratamentos com omissão de nitrogenio e magnésio inferior.

Comparando os tratamentos entre si, pelo teste de Tuckey ao nível de 5\% também somente no primeiro grupo foi constatado diferenças significativas. Os tratamentos com omissão de $\mathrm{N}$ e $\mathrm{Mg}$, mostraram-se inferiores aos demais e o tratamento com omissão de cálcio superior em concentração de magnésio sobre os outros, com exceção do tratamento completo.

A mais baixa concentração foi constatada no tratamento em que foi omitido o nitrogenio, seguido pelo tratamento com omissão de magnésio.

\section{Distribuição percentual de enxofre nos limbos das folhas nos diferentes tratamentos}


Tabela 11 - Percentagem de enxofre nos limbos das folhas nos diferentes tratamentos

\begin{tabular}{c|cc}
\hline \multirow{2}{*}{ Tratamentos } & \multicolumn{3}{|c}{ limbo } \\
\cline { 2 - 3 } & velho & novo \\
\hline \hline$-\mathrm{N}$ & 0,899 & 0,471 \\
$-\mathrm{P}$ & 1,358 & 0,575 \\
$-\mathrm{Ca}$ & 0,904 & 0,434 \\
$-\mathrm{Mg}$ & 0,832 & 0,428 \\
$-\mathrm{Fe}$ & 1,022 & 0,647 \\
$-\mathrm{S}$ & 0,542 & 0,167 \\
$-\mathrm{K}$ & 0,798 & 0,460 \\
\hline $\mathrm{C}$ & 0,981 & 0,810 \\
Teste Dunnett & $(0,669)$ & $(0,349)$ \\
Teste Tuckey & $(0,669)$ & $(0,349)$ \\
C.V. & $(27,96)$ & $(31,75)$ \\
\hline
\end{tabular}

\section{Percentagem de enxôfre no limbo}

\section{a) Percentagem de enxofre no limbo velho}

Comparando o tratamento completo com os tratamentos deficientes, houve apenas diferença entre o tratamento com omissão de enxofre e aquele com omissão de fósforo, este último com concentração maior de enxofre. Observou-se maiores concentrações de enxofre nos limbos velhos de todos os tratamentos.

\section{b) Percentagem de enxofre no limbo novo}

Comparando o tratamento completo com os tratamentos deficientes, aquele é superior aos tratamentos com omissão de $\mathrm{S}, \mathrm{K}$, $\mathrm{Ca}$ e $\mathrm{Mg}$.

Comparando entre si os tratamentos deficientes, verificou-se que apenas os tratamentos com omissão de ferro e de fósforo foram superiores ao tratamento com omissão de enxofre.

Quantidade em Miligramas de Nitrogenio, Fósforo, Potássio, Cálcio, Magnésio e Enxofre, Aborvidas pelas plantas

Os dados dos tratamentos com omissões de $\mathrm{N}, \mathrm{P}, \mathrm{K}, \mathrm{Ca}$ e $\mathrm{Mg}$ foram analisados em conjunto, enquanto que o tratamento com omissão de $\mathrm{S}$ foi analisado em tres grupos, tal como se indicou em análises anteriores.

Os dados acham-se na Tabela 12). 


\section{Quantidade em miligramas de nitrogenio}

Comparando os tratamentos deficientes com o tratamento completo, pelo teste de Dunnett ao nível de 5\%, encontrou-se uma concentração menor nos tratamentos com omissões de $\mathrm{N}, \mathrm{Mg}$ e $\mathrm{S}$ em relação àquela encontrada no tratamento completo.

A comparação dos tratamentos entre si, pelos testes de Tuckey ao nível de 5\%, acusou efeitos significativos superiores aos tratamentos com omissões de $\mathrm{P}, \mathrm{Ca}, \mathrm{Fe}$ e $\mathrm{K}$ e o completo sobre o tratamento deficiente em $\mathrm{N}$.

Os outros tratamentos não apresentaram diferença significativa.

Observa-se na Tabela 12 que a mais alta concentração de nitrogenio encontra-se no tratamento com omissão de ferro e que esta quantidade é superior a encontrada no tratamento completo, apesar de não ser significativa essa diferença.

As quantidades de nitrogenio encontradas nos tratamentos com omissão de $\mathrm{S}$ e $\mathrm{Mg}$, apresentaram pouca diferença entre si. O mesmo acontece com os tratamentos com omissão de $\mathrm{P}$ e $\mathrm{Ca}$.

Como era de se esperar o tratamento com omissão de nitrogenio contém menor acúmulo de $\mathrm{N}(513,73 \mathrm{mg})$. O tratamento que apresenta maior quantidade de $\mathrm{N}$ é aquele em que foi omitido o $\mathrm{K}$.

Todos os tratamentos, embora algumas diferenças não sejam significativas tem valores inferiores ao tratamento completo.

\section{Quantidade em miligramas de fósforo}

Fazendo-se a comparação dos tratamentos deficientes com o tratamento completo, constatou-se que os tratamentos com omissões de $\mathrm{N}, \mathrm{P}$ e $\mathrm{Mg}$ são estatisticamente inferiores à quantidade de fósforo do que o completo.

Tabela 12 - Miligramas de N, P, K, Ca, Mg e S na planta completa

\begin{tabular}{l|r|r|r|r|r|r}
\hline \multirow{2}{*}{$\begin{array}{l}\text { mili- } \\
\text { grama }\end{array}$} & \multicolumn{7}{c}{ T R A T A M E N T O S } \\
\cline { 2 - 7 } & $-\mathrm{N}$ & $-\mathrm{P}$ & \multicolumn{1}{|c}{$-\mathrm{K}$} & $-\mathrm{Ca}$ & $-\mathrm{Mg}$ & $-\mathrm{S}$ \\
\hline $\mathrm{N}$ & 513,73 & 1407,69 & 1508,45 & 1401,57 & 1238,70 & 1245,86 \\
$\mathrm{P}$ & 188,68 & 121,24 & 476,28 & 403,21 & 328,74 & 451,85 \\
$\mathrm{~K}$ & 966,71 & 1921,80 & 1274,90 & 2266,34 & 2061,47 & 2533,61 \\
$\mathrm{Ca}$ & 325,32 & 749,83 & 1339,99 & 383,82 & 934,75 & 888,17 \\
$\mathrm{Mg}$ & 180,48 & 315,68 & 531,21 & 598,87 & 164,77 & 406,80 \\
$\mathrm{~S}$ & 169,95 & 348,15 & 327,97 & 331,30 & 275,55 & 192,75 \\
\hline
\end{tabular}




\begin{tabular}{|c|c|c|c|c|c|c|c|}
\hline \multirow{2}{*}{$\begin{array}{l}\text { mili- } \\
\text { gramas }\end{array}$} & \multicolumn{5}{|c|}{ TRA T A $\mathrm{EN}$ T O S } & & \\
\hline & $-\mathrm{Fe}$ & $\mathrm{C}_{1}$ & $\mathbf{C}_{2}$ & $\mathrm{C}_{3}$ & C & & \\
\hline $\mathbf{N}$ & $\begin{array}{r}1949,59 \\
641,75\end{array}$ & & & & $\begin{array}{r}1838,0 \\
535,70\end{array}$ & $\begin{array}{l}\text { Dunnett } \\
\text { Tuckey } \\
\text { Dunnett } \\
\text { Tuckey } \\
\text { C. V. }\end{array}$ & $\begin{array}{c}564,141 \\
787,446 \\
166,02 \\
231,79 \\
20,36 \%\end{array}$ \\
\hline $\mathrm{K}$ & 2945,21 & & & & 3088,20 & $\begin{array}{l}\text { Dunnett } \\
\text { Tuckey } \\
\text { C. V. }\end{array}$ & $\begin{array}{r}865,734 \\
208,420 \\
19,18 \%\end{array}$ \\
\hline $\mathrm{Ca}$ & 1232,02 & & & & 1051,28 & $\begin{array}{l}\text { Dunnett } \\
\text { Tuckey } \\
\text { C. V. }\end{array}$ & $\begin{array}{c}330,299 \\
461,043 \\
19,14 \%\end{array}$ \\
\hline $\mathrm{Mg}$ & 523,29 & & & & 490,58 & $\begin{array}{l}\text { Dunnett } \\
\text { Tuckey } \\
\text { C.V. }\end{array}$ & $\begin{array}{c}162,533 \\
226,870 \\
20,23 \%\end{array}$ \\
\hline $\mathbf{S}$ & 517,46 & 491,96 & 556,43 & 497,84 & & $\begin{array}{l}\text { Dunnett } \\
\text { Tuckey } \\
\text { C. V. }\end{array}$ & $\begin{array}{c}248,95 \\
347,50 \\
34,36 \%\end{array}$ \\
\hline
\end{tabular}

Comparando os tratamentos entre si pelo teste de Tuckey ao nível de $5 \%$, constatou-se que todos os tratamentos, com exceção daqueles em que foram omitidos $\mathrm{N}$ e $\mathrm{Mg}$, apresentam quantidade em $\mathrm{P}$ superior ao tratamento na qual foi omitido esse elemento. $\mathrm{O}$ tratamento com omissão de $\mathrm{Fe}$, que apresenta a maior concentração de $\mathrm{P}$ é superior estatisticamente aos tratamentos deficientes em $\mathrm{Mg}, \mathrm{Ca}, \mathrm{N}$ e aqueles já citados, $\mathrm{P}$. Por outro lado, o tratamento com omissão de $\mathrm{N}$ ainda é inferior ao tratamento completo e aqueles em que foram omitidos $\mathrm{K}$ e $\mathrm{S}$, essa diferença também é significativa.

A quantidade mais baixa absorvida, como é óbvio, foi encontrada no tratamento onde foi omitido o $\mathrm{P}(121,24 \mathrm{mg})$.

Os tratamentos com omissão de $\mathrm{K}$ e $\mathrm{S}$, apresentaram quantidade quase semelhantes ao tratamento com omissão de $P$.

\section{Quantidade em miligramas de potássio}

Comparando o tratamento completo com os demais, pelo teste de Dunnett ao nível de 5\%, constatou-se que os tratamentos deficientes em $\mathrm{N}, \mathrm{P}, \mathrm{Mg}$ e $\mathrm{K}$ apresentaram quantidade de $\mathrm{K}$ inferior ao tratamento completo.

A comparação dos tratamentos deficientes entre si, pelo teste 
de Tuckey ao nível de 5\%, acusou as seguintes diferenças estatisticamente significativas: o tratamento com omissão de Fe, que apresenta a maior quantidade de $\mathrm{K}$ entre os deficientes, contém quantidade de $\mathrm{K}$ superior àquelas $\mathrm{em}$ que foram omitidos este elemento e nitrogenio. Este último, por sua vez apresenta ainda quantidade inferior aos tratamentos deficientes em cálcio e enxofre.

A menor quantidade de potássio verificou-se no tratamento com omissão de nitrogenio e não onde se omitiu o elemento em estudo como era de se esperar.

Os tratamentos com omissão de fósforo e potássio diferenciaram-se muito pouco entre si.

Entre os tratamentos com omissão de cálcio e enxofre, existe uma apreciável diferença, que apesar de não ser significativa estatisticamente, é bastante notória em relação aos demais tratamentos.

\section{Quantidade em miligramas de cálcio}

Comparando os tratamentos deficientes com o completo, pelo teste de Dunnett ao nível de $5 \%$, constatou-se que neste último a quantidade de cálcio é superior aos tratamentos com omissão de nitrogenio e cálcio.

Confrontando os tratamentos deficientes entre si pelo teste de Tuckey ao nível de $5 \%$, verificou-se que os tratamentos com omissões de $\mathrm{K}$ e $\mathrm{Fe}$ apresentaram quantidade de cálcio superior aos tratamentos deficientes em P, N e Ca. Estes dois últimos ainda são inferiores, em quantidade de cálcio do que os tratamentos com omissão de magnésio e enxofre.

Como no caso anterior (K), a menor quantidade de $\mathrm{Ca}$ foi encontrada no tratamento com omissão de nitrogenio e não naquele em que foi omitido o cálcio.

O tratamento com omissão de potássio apresentou maior quantidade de cálcio.

\section{Quantidade em miligramas de magnésio}

Comparando o tratamento completo com os demais, pelo teste de Dunnett ao nível de 5\%, verificou-se que aquele apresenta quantidade maior de magnésio que os tratamentos com omissão de $\mathrm{N}$, $\mathrm{P}$ e $\mathrm{Mg}$.

Comparando-se os tratamentos entre si, pelo teste de Tuckey ao nível de $5 \%$, os tratamentos com omissão de $\mathrm{K}$, Ca e Fe acusaram superioridade em quantidade de magnésio em relação aqueles em que foram omitidos $\mathrm{N}$ e $\mathrm{Mg}$. Este último é ainda inferior em quan- 
tidade do que tratamento com omissão de enxofre. Outra diferença significativa foi encontrada entre os tratamentos com omissão de $\mathrm{P}$ e $\mathrm{Ca}$, sendo este superior àquele .

o tratamento que apresentou maior quantidade de magnésio foi aquele em que foi omitido cálcio e como era de se esperar, menor naquele com omissão de magnésio.

\section{Quantidade em miligramas de enxofre}

Os tratamentos foram analisados em tres grupos distintos.

No primeiro grupo, apenas os tratamentos com omissões de $\mathrm{N}$ e $\mathrm{Mg}$ apresentaram quantidades menores de enxofre que o tratamento completo e essas diferenças são significativas pelo teste de Dunnett ao nível de 5\%.

No segundo grupo não houve diferença significativa entre o tratamento completo com aquele com omissão de Fe.

O tratamento com omissão de enxofre e potássio apresentaram quantidade de enxofre inferiores ao tratamento completo e essa diferença é significativa pelo teste de Dunnett ao nível de 5\%.

A comparação dos tratamentos deficientes entre si pelo teste de Tuckey ao nível de 5\% assinalou que a quantidade de enxofre encontrada no tratamento com omissão de potásio é superior àquela encontrada no tratamento deficiente do nutriente em estudo.

A mais alta concentração foi encontrada no tratamento com omissão de ferro, e esta quantidade é ligeiramente inferior à do tratamento completo, enquanto que a menor concentração não foi no tratamento com omissão de enxofre $(192,75 \mathrm{mg})$ como deveria ser, e sim naquele em que foi omitido o nitrogenio $(169,95 \mathrm{mg})$.

Os tratamentos com omissão de fósforo, potássio e cálcio apresentam quantidades semelhantes de enxofre.

\section{CONCLUSÕES}

As observações feitas e os dados obtidos permitem tirar as seguintes conclusões:

1 - os sintomas de deficiências de nitrogenio, de potássio, de enxofre, de ferro, não diferem daqueles da maioria das plantas, enquanto que os sintomas de deficiências de fósforo, do cálcio e do magnésio diferem daqueles normalmente manifestados em plantas deficientes naqueles nutrientes.

2 - em relação à altura das plantas, aquelas deficientes em nitrogenio, fósforo e magnésio acusaram uma diminuição de $52 \%$, 
$53 \%$ e $53 \%$ respectivamente quando comparadas com as plantas do tratamento completo. O aumento na altura dos outros tratamentos não diferiram estatisticamente do tratamento completo.

No que diz respeito ao diametro do caule, o tratamento com omissão do nitrogenio acusou menor diametro. Os tratamentos com omissões de nitrogenio e de potássio tem o menor comprimento do lóbulo central.

3 - no que concerne à percentagem dos macronutrientes nos limbos das folhas velhas e novas, verifica-se o seguinte: a) no tratamento onde omitiu-se o nitrogenio, a percentagem deste nutriente encontrado foi de 2,26 e de 2,72 nos limbos das folhas velhas e novas respectivamente, enquanto que no tratamento completo, as concentrações foram de $2,72 \%$ e $2,94 \%$ de nitrogenio para os limbos das folhas velhas e novas respectivamente; b) os limbos das folhas velhas e novas das plantas deficientes em fósforo, as concentrações deste nutriente foram de $0,25 \%$ e $0,15 \%$ respectivamente, enquanto que no tratamento completo as concentrações daquele nutriente foram de $0,53 \%$ e de $0,52 \%$ nos limbos das folhas velhas e novas respectivamente; c) o nível de potássio nos limbos das folhas velhas e novas foi de $1,90 \%$ e $1,09 \%$ respectivamente nas plantas onde $o$ nutriente foi omitido e de $3,31 \%$ e de $2,61 \%$ nos limbos das folhas velhas e novas respectivamente das plantas do tratamento completo; d) as concentrações de cálcio foram $1,01 \%$ e $0,23 \%$, respectivamente, nos limbos das folhas velhas e novas das plantas deficientes neste nutriente. No tratamento completo, as concentrações foram de $2,10 \%$ e $1,47 \%$ nos limbos das folhas velhas e novas respectivamente. Convém frisar, aqui, que a maior concentração de cálcio. foi encontrada nos limbos das folhas velhas e novas das plantas deficientes em potássio; e) no tratamento com omissão de magnésio, as concentrações desde nutriente foram de $0,37 \%$ e $0,17 \%$, respectivamente, nos limbos das folhas velhas e novas; no tratamento completo estas concentrações foram de $0,67 \%$ e $0,55 \%$ nos limbos das folhas velhas e novas respectivamente; f) concentrações de $0,54 \%$ e de $0,17 \%$ de enxofre foram encontradas nos limbos das folhas velhas e novas plantas deficientes neste nutriente; no tratamento completo, as concentrações foram de $0,98 \%$ e $0,81 \%$ nos limbos das folhas velhas e novas respectivamente.

Com exceção das concentrações de fósforo, no tratamento completo, que foram iguais para os limbos das folhas velhas e novas, todas as demais concentrações dos outros nutrientes foram maiores para os limbos das folhas velhas.

4 - No que tange à absorção ou melhor à extração dos macronutrientes, infere-se que: 
a) a planta com os tratamentos completos e com omissão de ferro absorveram $1838,40 \mathrm{mg}$ e $1949,59 \mathrm{mg}$ de nitrogenio respectivamente. Quantidades menores absorvidas em ordem descendente foram encontradas nos tratamentos com omissões de $\mathrm{K}, \mathrm{P}, \mathrm{Ca}, \mathrm{S}$ e $\mathrm{Mg}$. As planta deficiente em nitrogenio extraiu $513,73 \mathrm{mg}$ deste nutriente.

b) Os tratamentos completos e com omissão de ferro absorveram $535,70 \mathrm{mg}$ de fósforo e $641,75 \mathrm{mg}$ de fósforo respectivamente.

Quantidades menores do que o tratamento completo, em ordem decrescente foram absorvidas pelas plantas dos tratamentos deficientes em $\mathrm{K}, \mathrm{S}, \mathrm{Ca}, \mathrm{Mg}$ e $\mathrm{N}$. A planta sem $\mathrm{P}$, como é óbvio, absorveu menor concentração de fósforo $(121,24 \mathrm{mg})$.

c) o tratamento completo absorveu a maior quantidade de potássio $(388,20 \mathrm{mg})$.

O tratamento - Fe absorveu (2945,21 mg) uma quantidade menor, e os tratamentos com omissões de $\mathrm{S}, \mathrm{Ca}, \mathrm{Mg}, \mathrm{P}$ e $\mathrm{K}$ quantidades menores ainda que aquela do tratamento completo.

O tratamento onde foi omitido o magnésio acusou, como é óbvio, potássio que todos os outros tratamentos.

d) os tratamentos com omissões de potássio e ferro acusaram $1339,99 \mathrm{mg}$ e $1232,02 \mathrm{mg}$ de cálcio respectivamente, quantidades maiores do que aquela da planta do tratamento completo $(1051,28 \mathrm{mg})$. Houve menor absorção de cálcio nos outros tratamentos em relação aquela do tratamento completo.

Os tratamentos onde foram omitidas o cálcio e o nitrogenio apresentaram menores quantidades deste nutriente $383,82 \mathrm{mg}$ e 325,32 mg respectivamente.

e) os tratamentos $-\mathrm{Ca},-\mathrm{K}$ e $-\mathrm{Fe}$ são aqueles que absorveram maiores quantidades $(598,87 \mathrm{mg}-531,21 \mathrm{mg}-523,29 \mathrm{mg}) \mathrm{de}$ magnésio respectivamente. O tratamento completo absorveu 493,58 mg de magnésio.

O tratamento onde foi omitido o magnésio acusou, como é óbvio, a menor quantidade $(164,45 \mathrm{mg}$ de magnésio).

f) os tratamentos completo e sem $\mathrm{Fe}$ absorveram quantidades de enxofre oscilando entre $491,96 \mathrm{mg}, 556,4 \mathrm{mg}$ e $517,46 \mathrm{mg}$.

Os tratamentos que menos enxofre absorveram foram aaueles nos quais foram omitidos este nutriente e o nitrogenio, $192,75 \mathrm{mg}$ e $169,95 \mathrm{mg}$, respectivamente.

5 - Tornando $\mathrm{N}=1$, a relação entre os nutrientes dos diferentes tratamentos foi o seguinte: 


\begin{tabular}{l}
\multicolumn{70}{l}{ nutrientes } \\
\hline \hline \\
\hline
\end{tabular}

A relação entre os nutrientes para os tratamentos, completo, sem $N$, sem $P$ e sem Fe é quase identico apesar da ausencia deste nutriente. Por outro lado, nos tratamentos sem $\mathrm{K}$ e sem $\mathrm{Mg}$, a relação aumenta a favor do $\mathrm{Ca}$ principalmente e no tratamento sem $\mathrm{S}$, a relação aumenta a favor do $\mathrm{K}$ e do $\mathrm{Ca}$.

\section{SUMMARY}

EFFECT OF MACRONUTRIENTS AND IRON UPON THE GROWTH AND MINERAL COMPOSITION OF CASTOR BEAN (Ricinus

\section{Communis L.) CULTIVATED IN NUTRIENT SOLUTION}

This work was accomplished with the aim of studying the effects of macronutrients and iron on the growth and chemical composition of the Castor Bean (Ricinus Communis L.) cultivated in nutritive solution.

Castor bean seedlings were cultivated during 2 months in complete solution and afterwards were transferred to nutritive solutions with and without the presence of macronutrients and iron (micronutrient).

After 2 months of cultivation in deficient solutions, symptoms of lack of $\mathrm{N}, \mathrm{P}, \mathrm{K}, \mathrm{Ca}, \mathrm{Mg}, \mathrm{S}$ and $\mathrm{Fe}$ were found and described in this work.

As soon as symptoms of deficiency appeared, the plants were harvested and divided in the following fractions: root, old stem, (the portion marked at the time of application of the deficient solution), new stem (the portion grown above the mark), old petioles, new petioles, old leaves, new leaves and fruits. 
With respect to the development of the plants the following measurements were taken: height, stem diameter, length of central "lobulo" taken from the center of the leaf. Each one of the fractions was also weighed.

The $\mathrm{N}, \mathrm{P}, \mathrm{K}, \mathrm{Ca}, \mathrm{Mg}, \mathrm{S}$ and $\mathrm{Fe}$ macronutrients concentrations were determined from the old and new leaves and from the total plants. The quantities in $\mathrm{mg}$ of each one of these macronutrients absorved by the plant were calculated.

\section{LITERATURA CITADA}

CANECCHIO, V., 1958. Melhoramento da Mamoeira (Ricinus communis, L.) Bragantia, 17 (24): 331-343.

HOGLAND and ARNON, D. 1950 The water Culture Method for Growing Plants Without Soil. Circular n. ${ }^{\circ} 347$. University of California, Berkeley. KRUG, C. A. and MENDES, P. T. 1942. Melhoramento da Mamoneira (Ricinus communis L.) Bragantia, 2 (5): 129-197.

LOTT, W. L. J. P., GALLO, R.J., MEDCALF, J. J. 1956. A técnica de Análise Foliar Aplicado ao Cafeeiro. Boletim 79 do Instituto Agronômico de Campinas.

MIALHE, L. G. 1969. Estudo de um Mecanismo Descascador de Mamona. (Ricinus communis, L.) Tese de Doutoramento, Escola Superior de Agricultura "Luiz de Queiroz", USP - Piracicaba.

MALAVOLTA, E. 1964. Análises Químicas dos Teores Totais. Curso Internacional de Diagnose Foliar. IICA, ESALQ. Piracicaba (mim.).

MALAVOLTA, E. 1967. Manual de Química Agrícola. Adubos e Adubações. Biblioteca Agronômica Ceres Ltda. Ceres Editora. 2. ${ }^{a}$ edição. São Paulo - Brasil.

NAKAME, I. J. $1968 . \quad$ Caderno Regional da Bahia, Coopercotia, 25 (226): 15-32.

NEPTUNE MENARD, L. 1956. Efeitos do Fósforo e de Alguns Micronutrientes no crescimento e Composição Química do Cafeeiro (Coffea arabica L Var. Caturra K. M. C. ) cultivado em solução nutritiva. Tese de Doutoramento. Piracicaba, Escola Superior de Agricultura "Luiz de Queiroz" - U.S.P. - 64 páginas.

PEARSON, E. S. \& HAR'ILEY, H. O 1956. Biometrika Tables for Staticians. Vol. I. Pág. 57-61. Publ. by The Syndics of the Cambridge University Press.

PIMENTEL GOMES, F. 1966. Curso de Estatística Experimental. Universidade de São Paulo - ESALQ - 3. ${ }^{\mathrm{a}}$ edição. Piracicaba.

STEEL, R. G. D. and TORRIE, J. H. 1960. Principles and Procedures of Statistical. Mc Graw-Hill Book Company Inc. New York, I'oronto London.

SCHOENLEBER, L. G. 1960. Machines for New Crops Power to Produce. In the Yearbook of Agricultural, USDA, Washington, D.C.U.S.A. pag. 434-439.

TUCKER, B. B. 1952 . Castor Beans: Their Nutrient Requirements, Responses to F'ertilization Treatments, and Deficiency Symtoms Under Controlled Conditions. Thesis M. S., Oklahoma Agric. and Mech College Stillwater, Oklahoma.

VASCONCELLOS, R. J. L. 1964. Novas possibilidades para o cultivo da Mamoneira. O Agronomico. 16 ( 5 e 6 ).

ZIMMERMAN, H. L. 1958. Castor Beans: A. New Oil Crop for Mechanized Production Advances in Agronomy, 258-287. 
